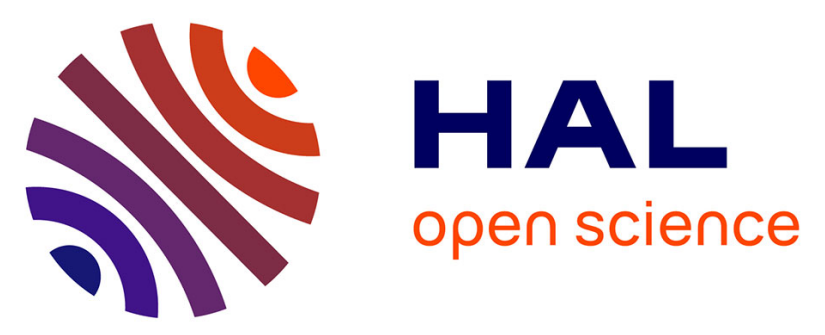

\title{
Azide-Coordination in Homometallic Dinuclear Lanthanide(III) Complexes Containing Nonequivalent Lanthanide Metal Ions: Zero-Field SMM Behavior in the Dysprosium Analogue
}

Pawan Kumar, Sourav Biswas, Abinash Swain, Joydev Acharya, Vierandra Kumar, Pankaj Kalita, Jessica Flores Gonzalez, Olivier Cador, Fabrice Pointillart, Gopalan Rajaraman, et al.

\section{- To cite this version:}

Pawan Kumar, Sourav Biswas, Abinash Swain, Joydev Acharya, Vierandra Kumar, et al.. AzideCoordination in Homometallic Dinuclear Lanthanide(III) Complexes Containing Nonequivalent Lanthanide Metal Ions: Zero-Field SMM Behavior in the Dysprosium Analogue. Inorganic Chemistry, 2021, 60 (12), pp.8530-8545. 10.1021/acs.inorgchem.1c00249 . hal-03282730

\author{
HAL Id: hal-03282730 \\ https://hal.science/hal-03282730
}

Submitted on 15 Sep 2021

HAL is a multi-disciplinary open access archive for the deposit and dissemination of scientific research documents, whether they are published or not. The documents may come from teaching and research institutions in France or abroad, or from public or private research centers.
L'archive ouverte pluridisciplinaire HAL, est destinée au dépôt et à la diffusion de documents scientifiques de niveau recherche, publiés ou non, émanant des établissements d'enseignement et de recherche français ou étrangers, des laboratoires publics ou privés. 


\section{Azide-Coordination in Homometallic Dinuclear Lanthanide(III) Complexes Containing}

Non-Equivalent Lanthanide Metal Ions: Zero-Field SMM Behavior in the Dysprosium

\section{Analogue}

Pawan Kumar, ${ }^{a}$ Sourav Biswas, ${ }^{b}$ Abinash Swain, ${ }^{c}$ Joydev Acharya, ${ }^{a}$ Vierandra Kumar, ${ }^{a}$ Pankaj Kalita, ${ }^{d}$ Jessica Flores Gonzalez, ${ }^{e}$ Olivier Cador, ${ }^{e}$ Fabrice Pointillart, *e Gopalan Rajaraman ${ }^{* c}$ and Vadapalli Chandrasekhar*a,d

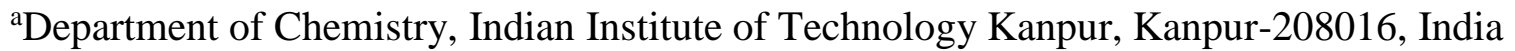

bepartment of Geo-Chemistry, Keshav Deva Malaviya Institute of Petroleum Exploration, Dehradun-248915, India.

${ }^{\mathrm{c}}$ Department of Chemistry, Indian Institute of Technology Bombay, Powai, Mumbai 400076.

${ }^{\mathrm{d}}$ Tata Institute of Fundamental Research, Gopanpally, Hyderabad - 500 107, India, eUniv Rennes, CNRS, ISCR (Institut des Sciences Chimiques de Rennes) - UMR 6226, F-35000 Rennes, France.

AUTHOR EMAIL ADDRESS: vc@iitk.ac.in; vc@tifrh.res.in; fabrice.pointillart@univrennes1.fr; rajaraman@chem.iitb.ac.in 


\begin{abstract}
A series of homometallic dinuclear lanthanide(III) complexes containing non-equivalent lanthanide metal centres $\left[\mathrm{Ln}_{2}\left(\mathrm{LH}_{2}\right)(\mathrm{LH})\left(\mathrm{CH}_{3} \mathrm{OH}\right)\left(\mathrm{N}_{3}\right)\right] \cdot \mathrm{xMeOH} \cdot \mathrm{yH}_{2} \mathrm{O}\left[\mathbf{1}, \mathrm{Ln}=\mathrm{Dy}{ }^{\mathrm{III}}, \mathrm{x}=0, \mathrm{y}=\right.$ 2; $\left.2, \mathrm{Ln}=\mathrm{Tb}^{\mathrm{III}}, \mathrm{x}=1, \mathrm{y}=1\right]$ have been synthesized $\left[\mathrm{LH}_{4}=6\right.$-((bis(2-hydroxyethyl)amino)- $N^{\prime}$-(2hydroxybenzylidene)picolinohydrazide] and characterized. The dinuclear assembly contains two different types of nine-coordinated lanthanide centers due to the non-equivalent binding of the azide co-ligand as well as the varying coordination of the de-protonated Schiff base ligand. Detailed magnetic studies have been carried out on the complexes $\mathbf{1}$ and 2. Complex $\mathbf{1}$ and its

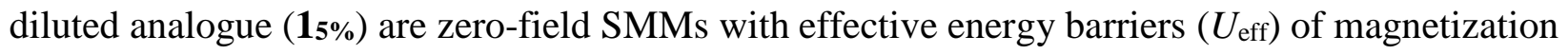
reversal equal to $59(3) \mathrm{K}$ and $66(3) \mathrm{K}$ and relaxation times of $\tau_{0}=10(4) \times 10^{-6} \mathrm{~s}$ and $10(4) \times 10^{-8} \mathrm{~s}$, respectively. On the other hand, complex 2 shows a field-induced SMM behavior. Combined $a b$ initio and DFT calculations were performed to explain the experimental findings and to unravel the nature of the magnetic anisotropy, exchange-coupled spectra and magnetic exchange interactions between the two lanthanide centers.
\end{abstract}

Keywords: lanthanide complexes, magnetic anisotropy, Schiff base, single molecule magnets, magnetic measurement, azide. 


\section{Introduction}

Single-molecule magnets (SMMs) are discrete molecular complexes comprising 3d/4d/5d/4f/5f metal ions or a combination thereof such as $3 \mathrm{~d} / 4 \mathrm{f}$ heterometallic complexes which can be magnetized upon application of a magnetic field and which retain their magnetization below a certain temperature known as the blocking temperature $\left(T_{\mathrm{B}}\right) .{ }^{1}$ These systems show slow relaxation of magnetization which depends on an energy barrier ( $\left.U_{\text {eff }}\right)$ for the magnetization reversal. ${ }^{2}$ For molecules to display SMM behavior, there is a requirement of a large ground spin state (S) and an Ising type anisotropy. Among the various types of complexes investigated, complexes containing lanthanide metal ions are most promising owing to these having a large ground state single ion magnetic anisotropy which results from a very high spin-orbit coupling. In addition many lanthanide ions such as $\mathrm{Dy}{ }^{\mathrm{III}}$ and $\mathrm{Tb}^{\mathrm{III}}$ have a reasonable ground state spin because of the presence of sufficient number of unpaired electrons. ${ }^{3}$ The investigations on lanthanide complexes as SMMs began with Isikawa's seminal discovery of slow relaxation of magnetization in the sandwich complex $\left[\mathrm{Bu}_{4} \mathrm{~N}\right]\left[\mathrm{TbPc}_{2}\right] .{ }^{4}$ It was quickly realized that lanthanide ions with their intrinsic unquenched orbital angular momenta could contribute to magnetic anisotropy. In recent years, a large number of lanthanide-based SMMs with very high effective energy barriers of magnetization above $1000 \mathrm{~K}^{5}$ and blocking temperatures up to $80 \mathrm{~K}^{6}$ have been reported. While the mononuclear Dy ${ }^{\text {III }}$ complexes yielded very attractive blocking temperatures in recent years, the axial limit set by the ligand field has already been breached for mononuclear complexes. Therefore, expanding the structural motif beyond monomers is of importance. ${ }^{7}$ Among these systems dinuclear complexes are of interest because these allow an understanding of the interactions between the two lanthanide ions. ${ }^{8}$ The magnetic coupling between the lanthanide ions can generate an exchange

\section{ACCEPTED MANUSCRIPT}


bias field that could minimize the quantum tunneling of the magnetization. ${ }^{9}$ Among such dinuclear complexes those containing non-equivalent lanthanide ions are especially sparse. ${ }^{8 \mathrm{a}, 10}$

We have been involved in the design of polydentate ligands for assembling various types of lanthanide complexes whose nuclearity varied from 1 to $21 .{ }^{11}$ In these efforts we found, similar to some other groups, that aroylhydrazone-based Schiff base ligands are particularly efficient in the construction of lanthanide complexes. ${ }^{12}$ We have synthesized a pyridine-based Schiff base ligand $\left(\mathrm{LH}_{4}\right)$ and utilized it for preparing lanthanide complexes. Further, we were also interested in incorporating the azide ligand in the assembly of these complexes in view of its demonstrated coordination motif versatility in transition metal complexes. ${ }^{13}$ Although, we anticipated a bridging coordination action from the azide ligand, as discussed below, we observe that this ligand binds in a monodentate fashion as a terminal ligand. Accordingly, herein, we report the synthesis, structural characterization and magnetic studies of $\left[\mathrm{Ln}_{2}\left(\mathrm{LH}_{2}\right)(\mathrm{LH})\left(\mathrm{CH}_{3} \mathrm{OH}\right)\left(\mathrm{N}_{3}\right)\right] \cdot \mathrm{xMeOH} \cdot \mathrm{yH}_{2} \mathrm{O}$ [ 1, Ln $=$ Dy $\left.{ }^{\mathrm{III}}, \mathrm{x}=0, \mathrm{y}=2 ; 2, \mathrm{Ln}=\mathrm{Tb}^{\mathrm{III}}, \mathrm{x}=1, \mathrm{y}=1\right]$. Although we have prepared the Gd(III) analogue (3), we were unable to establish the bulk purity of this compound. However, we were able to get single crystals in some quantity. We could perform the structural study which are presented in the Supporting Information. Among these complexes, the Dy ${ }^{\mathrm{III}}$ analogue is a zerofield SMM. Also, while the Dy ${ }^{\mathrm{III}}$ analogue has been shown to have antiferromagnetic interaction between the two $\mathrm{Dy}{ }^{\mathrm{III}}$ centres, the $\mathrm{Tb}^{\mathrm{III}}$ analogue has been shown to possess ferromagnetic interactions. These conclusions were possible by a theoretical study of the Gd(III) analogue. The differences between the $\mathrm{Dy}(\mathrm{III})$ and $\mathrm{Tb}(\mathrm{III})$ derivatives could be correlated to small structural changes in these complexes. All of these aspects are discussed herein through combined experimental and $a b$ initio theoretical calculations.

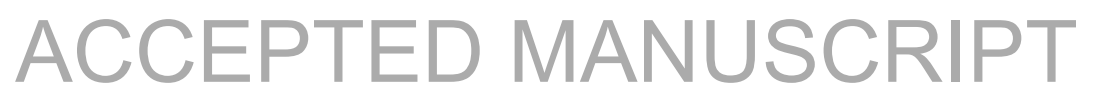




\section{Experimental Section}

Solvents and other general reagents used in this work were purified according to standard procedures. ${ }^{14}$ Pyridine-2,6-dicarboxylic acid, sodium borohydride, sodium azide, $\mathrm{DyCl}_{3} \cdot 6 \mathrm{H}_{2} \mathrm{O}$, $\mathrm{TbCl}_{3} \cdot 6 \mathrm{H}_{2} \mathrm{O}$ and $\mathrm{GdCl}_{3} \cdot 6 \mathrm{H}_{2} \mathrm{O}$ were obtained from Sigma Aldrich Chemical Co. and were used as received. Diethanolamine, hydrazine hydrate (80\%), $\mathrm{PBr}_{3}$, and sodium sulphate (anhydrous) were obtained from S.D. Fine Chemicals, Mumbai, India. Methyl-6-(hydroxymethyl) picolinate, ${ }^{15}$ methyl 6-(bromomethyl)picolinate, ${ }^{15}$ methyl-6-((bis(2-hydroxyethyl)amine)methyl)picolinate, ${ }^{11 \mathrm{~d}}$ and 6-((bis(2-hydroxyethyl)amino)methyl)picolinohydrazide $\left(\mathrm{A}_{5}\right),{ }^{11 \mathrm{~d}}$ were prepared according to literature procedure.

\section{Instrumentation}

Melting points were measured using a JSGW melting point apparatus and are uncorrected. IR spectra were recorded as $\mathrm{KBr}$ pellets on a Bruker Vector 22 FT IR spectrophotometer operating at 400-4000 $\mathrm{cm}^{-1}$. Elemental analyses of the compounds were obtained from Thermoquest CE instruments CHNS-O, EA/110 model. ESI-MS spectra were recorded on a MICROMASS QUATTRO II triple quadrupole mass spectrometer. ${ }^{1} \mathrm{H}$ NMR spectra were recorded in $\mathrm{CDCl}_{3}$ and DMSO-d $\mathrm{d}^{6}$ solutions on a JEOL JNM LAMBDA 400 model spectrometer operating at $500.0 \mathrm{MHz}$, Chemical shifts are reported in parts per million (ppm) and are referenced with respect to internal tetramethylsilane $\left({ }^{1} \mathrm{H}\right)$. A powder X-ray diffraction study was done on 1-2 with Bruker D8 Advance powder X-ray diffractometer. The samples for study were prepared by finely ground the crystals of 1-2 to powder form.

\section{X-ray Crystallography}

Single crystal data for the complexes were collected on a Bruker SMART CCD diffractometer ( $\mathrm{MoK}_{\alpha}$ radiation, $\lambda=0.71073 \AA$ ). The program $S M A R T^{16}$ was used for collecting frames of data,

\section{ACCEPTED MANUSCRIPT}


indexing reflections, and determining lattice parameters, SAINT for integration of the intensity of reflections and scaling, SADABS ${ }^{17}$ for absorption correction, and SHELXTL ${ }^{18}$ for space group and structure determination and least-squares refinements on $F^{2}$. On the other hand X-ray diffraction data for complex 1y was collected at low temperature (120 K) by using Rigaku diffractometer with graphite-monochromated molybdenum $\mathrm{K} \alpha$ radiation, $\lambda=0.71073 \AA$. Data integration and reduction were processed with CrysAlisPro software. ${ }^{19}$.An empirical absorption correction was applied to the collected reflections with SCALE3 ABSPACK integrated with CrysAlisPro.The crystal structures were solved and refined by full-matrix least-squares methods against $F^{2}$ by using the program SHELXL-2014 ${ }^{20}$ using Olex-2 ${ }^{21}$ software. All the non-hydrogen atoms were refined with anisotropic displacement parameters. Hydrogen positions were fixed at calculated positions and refined isotropically. The crystallographic figures have been generated using Diamond 3.1e software. ${ }^{22}$ In addition, some disorderd solvent molecules was present in complex 1-2.We could not assign all the solvent molecules properly due to the disorder and weak residual Q peaks. So the Olex-2 mask program was performed to discard the disordered solvents molecules which give an electron density of around 18 and 26 leading to the presence of two water molecules in $\mathbf{1}$ and one methanol and one water 2 respectively. The Possible masked electron counts and void volumes has been included in the corresponding CIFs.

The crystal data, the cell parameters and ccdc information for all the complexes are summarized in Table 1 and Table S1.

Table 1. Crystal data and structure refinement parameters of 1-2

\begin{tabular}{|l|l|l|l|}
\hline & \multicolumn{1}{|c|}{$\mathbf{1}$} & \multicolumn{1}{c|}{$\mathbf{1}$} & \multicolumn{1}{c|}{$\mathbf{2}$} \\
\hline formula & $\mathrm{C}_{37} \mathrm{H}_{43} \mathrm{Dy}_{2} \mathrm{~N}_{11} \mathrm{O}_{9}$ & $\mathrm{C}_{37} \mathrm{H}_{43} \mathrm{Y}_{2} \mathrm{~N}_{11} \mathrm{O}_{9}$ & $\mathrm{C}_{37} \mathrm{H}_{43} \mathrm{~N}_{11} \mathrm{O}_{9} \mathrm{~Tb}_{2}$ \\
\hline $\mathrm{g} /$ mol & 1110.82 & 963.64 & 1139.69 \\
\hline $\begin{array}{l}\text { crystal } \\
\text { system }\end{array}$ & Monoclinic & Monoclinic & Monoclinic \\
\hline
\end{tabular}




\begin{tabular}{|c|c|c|c|}
\hline $\begin{array}{l}\text { space } \\
\text { group }\end{array}$ & $C 2 / c$ & $C 2 / c$ & $C 2 / c$ \\
\hline$a / \AA$ & $25.561(11)$ & $25.494(7)$ & 25.519(14) \\
\hline b/Å & $16.456(11)$ & $16.411(4)$ & $16.432(14)$ \\
\hline$c / \AA$ & 22.709(11) & $22.618(6)$ & 22.762(14) \\
\hline$\alpha\left({ }^{\circ}\right)$ & 90 & 90 & 90 \\
\hline$\beta\left(^{\circ}\right)$ & $90.605(2)$ & $90.366(2)$ & $90.779(10)$ \\
\hline$\gamma\left({ }^{\circ}\right)$ & 90 & 90 & 90 \\
\hline$V / \AA^{3}$ & 9552.4(9) & 9463.6(4) & 9544.6(11) \\
\hline$Z$ & 8 & 8 & 8 \\
\hline$\rho_{\mathrm{c}} / \mathrm{g} \mathrm{cm}^{-3}$ & 1.545 & 1.353 & 1.586 \\
\hline$\mu / \mathrm{mm}^{-1}$ & 3.162 & 2.499 & 3.003 \\
\hline$F(000)$ & 4368.0 & 3936.0 & 4512.0 \\
\hline $\begin{array}{l}\text { cryst size } \\
\left(\mathrm{mm}^{3}\right)\end{array}$ & $0.24 \times 0.15 \times 0.13$ & $0.11 \times 0.1 \times 0.08$ & $\begin{array}{l}0.24 \times 0.16 \times \\
0.012\end{array}$ \\
\hline $\begin{array}{l}2 \theta \text { range } \\
(\text { deg) }\end{array}$ & 4.628 to 56.518 & 5.28 to 57.92 & 5.662 to 56.616 \\
\hline $\begin{array}{l}\text { limiting } \\
\text { indices }\end{array}$ & $\begin{array}{l}-34<=\mathrm{h}<=34 \\
-21<=\mathrm{k}<=21 \\
-30<=\mathrm{l}<=30\end{array}$ & $\begin{array}{r}-33<=\mathrm{h}<=32 \\
-16<=\mathrm{k}<=22 \\
-30<=\mathrm{l}<=30\end{array}$ & $\begin{array}{c}-34<=\mathrm{h}<=34 \\
-21<=\mathrm{k}<=21 \\
-30<=\mathrm{l}<=30\end{array}$ \\
\hline $\begin{array}{l}\text { reflns } \\
\text { collected }\end{array}$ & 75597 & 78591 & 100713 \\
\hline ind reflns & $\begin{array}{l}11815 \text { [R(int) } \\
=0.0507]\end{array}$ & $\begin{array}{l}11502[R \text { (int) } \\
=0.0681]\end{array}$ & $\begin{array}{l}11827 \text { [R(int) } \\
=0.0417]\end{array}$ \\
\hline $\begin{array}{l}\text { Completen } \\
\text { ess to } \theta \\
(\%)\end{array}$ & 100 & 100 & 100 \\
\hline $\begin{array}{l}\text { refinement } \\
\text { method }\end{array}$ & $\begin{array}{l}\text { Full-matrix least- } \\
\text { squares on } F^{2}\end{array}$ & $\begin{array}{l}\text { Full-matrix least- } \\
\text { squares on } F^{2}\end{array}$ & $\begin{array}{l}\text { Full-matrix least- } \\
\text { squares on } F^{2}\end{array}$ \\
\hline $\begin{array}{l}\text { data/restra } \\
\text { ints/param } \\
\text { s }\end{array}$ & 11815/0/547 & $11502 / 12 / 545$ & 11827/12/545 \\
\hline $\begin{array}{l}\text { goodness- } \\
\text { of-fit on } \\
F^{2} \\
\end{array}$ & 1.029 & 1.033 & 1.060 \\
\hline $\begin{array}{l}\text { Final R } \\
\text { indices } \\
{[I>2 \theta(I)]}\end{array}$ & $\begin{array}{l}R_{1}=0.0218 \\
w R_{2}=0.0505\end{array}$ & $\begin{array}{l}R_{1}=0.0495 \\
w R_{2}=0.1148\end{array}$ & $\begin{array}{l}R_{1}=0.0227 \\
w R_{2}=0.0547\end{array}$ \\
\hline $\begin{array}{l}R \text { indices } \\
\text { (all data) }\end{array}$ & $\begin{array}{l}R_{1}=0.0286 \\
w R_{2}=0.0532\end{array}$ & $\begin{array}{l}R_{1}=0.0668 \\
w R_{2}=0.1197\end{array}$ & $\begin{array}{l}R_{1}=0.0265 \\
w R_{2}=0.0562\end{array}$ \\
\hline CCDC no. & 2026262 & 2058082 & 2026261 \\
\hline
\end{tabular}

\section{Magnetic Measurements}


The $d c$ magnetic susceptibility measurements were performed on solid polycrystalline samples with a Quantum Design MPMS-XL SQUID magnetometer between 2 and $300 \mathrm{~K}$ in applied magnetic field of 200 Oe for temperatures between 2-20 K, 2 kOe between 20 and $80 \mathrm{~K}$ and 10 kOe above. The sample was immobilized in a pellet made with Teflon tape. These measurements were all corrected for the diamagnetic contribution as calculated with Pascal's constants. The $a c$ magnetic susceptibility measurements were performed on Quantum Design MPMS-XL SQUID magnetometer in the frequency range of 1 to $1000 \mathrm{~Hz}$.

\section{Computational Details}

The $a b$ initio calculations have been performed using MOLCAS 8.2 software package using CASSCF/RASSI-SO/SINGLE_ANISO module. ${ }^{23}$ For POLY_ANISO simulations, the inputs were taken from the SINGLE_ANISO results. ${ }^{24}$ In the CASSCF step for Dy ${ }^{\text {III }}$ complex, nine electrons in seven $4 \mathrm{f}$ active orbitals and for $\mathrm{Tb}^{\mathrm{III}}$ complex eight electrons in seven $4 \mathrm{f}$ orbitals were taken into consideration. For 121 sextets and for 27 septets, 140 doublets and 195 quartet roots were taken into consideration in RASSI-SO step as established earlier by us and others. ${ }^{25}$ The basis sets are of ANO-RCC...8s7p4d3f2g1h TZVP level for the paramagnetic center $\mathrm{Ln}^{\mathrm{III}}$ and $\mathrm{Lu}^{\mathrm{III}}$, ANO-RCC...4s3p2d TZV quality for $\mathrm{O}$ and $\mathrm{N}$ atoms since they are coordinating to the metal ion and ANO-RCC...3s2p/ ANO-RCC...2s DZV level for the rest of the atoms. The relativistic effect was taken care of by taking DKH Hamiltonian. In order to save disk space, Cholesky decomposition has been incorporated for our calculations. ${ }^{23 a}$ Spin-orbit coupling was taken into account through the RASSI-SO module using the CASSCF functions as input states. From the SINGLE-ANISO computation, the $g$ tensor for the ground state and excited state, magnetic susceptibility, crystal field parameter and orientation of main magnetic axes have been obtained. ${ }^{26}$

\section{ACCEPTED MANUSCRIPT}


Lines model was employed to calculate the exchange interaction between two $\mathrm{Ln}^{\mathrm{III}}$ sites using POLY-ANISO program. ${ }^{27}$ The experimentally obtained susceptibility values were simulated with the POLY_ANISO calculated values to get the exchange interaction between the two $\mathrm{Ln}^{\mathrm{III}}$ centres for both 1 and 2.

The exchange values obtained through this method was further verified by density functional calculations using the Gaussian 09 program employing the DFT broken symmetry approach. ${ }^{28}$ For this approach, we have used B3LYP hybrid functional, with Cundari-Stevens (CS) relativistic effective core potential for Gd atom and TZV level of basis set for the rest of the atoms. ${ }^{29}$ Quadratic convergence method was followed to the most stable wave function. Since the $\mathrm{Dy}{ }^{\mathrm{III}}$ and $\mathrm{Tb}^{\mathrm{III}}$ ion are highly anisotropic paramagnetic systems, to reduce the complexity in using DFT methods, we have replaced the $\mathrm{Dy}^{\mathrm{III}}$ and $\mathrm{Tb}^{\mathrm{III}}$ ion in the corresponding $\mathrm{X}$-ray structure with $\mathrm{Gd}^{\mathrm{III}}$ ion and computed the Js using the DFT method and rescaled the Js later using appropriate spin to get the exchange values. ${ }^{30}$ By this approach, the difference in structural parameters, however small, can be captured in the estimation of $J$ values. Also, this being an independent method offers the possibility to cross-verify results obtained using the Lines model wherein the experimental susceptibility data is fit to the ab initio computed parameters to extract the Js. The exchange values for $\mathrm{Dy}^{\mathrm{III}} / \mathrm{Tb}^{\mathrm{III}}$ has been calculated by multiplying $5 / 7$ and $6 / 7$ with the exchange values obtained from DFT using Gd ${ }^{\mathrm{III}}$ ion. For the Gd(III) analogue , the exchange values were estimated by the use of broken symmetry calculation using ORCA 4.2 package. For this, TZVP level was used for Gd and for the rest of the atoms def2-SVP has been used.

\section{Synthesis}


Compounds $\mathrm{A}_{1}$ to $\mathrm{A}_{5}$ ( Scheme S1) were prepared according to literature procedures ${ }^{11 \mathrm{~d}, 15}$.

\section{6-((Bis(2-hydroxyethyl)amino)methyl)- $N^{\prime}$-(2-hydroxybenzylidene)picolinohydrazide (LH4)}

Salicylaldehyde $\left(\mathrm{A}_{6}\right) \quad(0.19 \mathrm{~g}, 1.6 \mathrm{mmol})$ was added to a solution of 6-((bis(2hydroxyethyl)amino)methyl)picolinohydrazide $\left(\mathrm{A}_{5}\right)(0.406 \mathrm{~g}, 0.0016 \mathrm{~mol})$ in ethanol with stirring. The reaction mixture was refluxed for 6 hours, cooled and the the solvent reduced in vacuo. The concentrated solution was kept in a refrigerator affording a white precipitate which was washed with diethyl ether and dried. This was shown to be 6-((bis(2-hydroxyethyl)amino)methyl)-N'-(2hydroxybenzylidene)picolinohydrazide $\left(\mathrm{LH}_{4}\right)$ (0.305, 76\%). Anal. Calcd. For $\mathrm{C}_{18} \mathrm{H}_{22} \mathrm{~N}_{4} \mathrm{O}_{4}$ (358.40): C, 60.32; H, 6.19; N, 15.63 Found: C, 60.58; H, 5.99; N, 15.52. Mp: $164{ }^{\circ} \mathrm{C}$

${ }^{1}$ HNMR (400 MHz,DMSO-d6) $\quad$ 12.12(s,1H,NH), 11.36(s,1H,Ph-OH), 8.86(s,1H,CH), 8.04(m,2H,Py- $H), \quad \delta=7.84(\mathrm{~d}, 1 \mathrm{H}, \mathrm{Py}-H), \quad$ 7.52(d,1H,Ph-H), 7.32(t,1H,Ph- $H), \quad 6.94(\mathrm{~m}, 2 \mathrm{H}, \mathrm{Ph}-H)$, 4.47(br,2H,OH) 3.95(s,2H,CH2), 3.50(t,4H,CH 2$), \quad 2.65\left(t, 4 \mathrm{H}, \mathrm{CH}_{2}\right)$, IR $(\mathrm{KBr}) \mathrm{cm}^{-1}: 3498(\mathrm{br})$, 3443 (br), 3176 (br), 2955 (s), 2880 (br), 2804 (s), 1675 (s), 1622 (s), 1594 (w), 1536 (s), 1491 (w), $1474(w), 1449$ (s), 1398 (w), 1380 (s), $1371(w), 1273($ s), $1244(w), 1222(w), 1169(w)$, 1154 (s), 1045 (s), 971 (s), 898 (s), 780 (w), 737 (s), 698 (w), 678 (s), 566 (w), 518 (s). ESI-MS m/z, ion: 359.1701, $\left(\mathrm{C}_{18} \mathrm{H}_{23} \mathrm{~N}_{4} \mathrm{O}_{4}\right)^{+}$.

\section{General Synthetic Procedure for the Preparation of the Complexes 1-2}

To a stirred solution of $\mathrm{LH}_{4}(0.040 \mathrm{~g}, 0.11 \mathrm{mmol})$, in methanol $(30 \mathrm{~mL}), \mathrm{LnCl}_{3} \cdot 6 \mathrm{H}_{2} \mathrm{O}(0.11 \mathrm{mmol})$ was added to give a yellow colored solution which was allowed to stir for 10 minutes at room temperature. Then, $\mathrm{NaN}_{3}(0.010 \mathrm{~g}, 0.15 \mathrm{mmol})$ was added followed by the addition of triethylamine (0.046 $\mathrm{mL}, 0.33 \mathrm{mmol})$. The reaction mixture was allowed to stir for 6-8 hours at room temperature. The reaction mixture was filtered and stripped off its solvent in vacuo affording a 
semi-solid yellow residue which was dissolved in methanol containing a few drops of chloroform. Suitable crystals for X-ray diffraction were obtained by slow evaporation of the solvents within a week. A similar synthetic method was employed for the preparation of the yttrium analogue, the diluted analogue of complex $\mathbf{1}(\mathbf{1} 5 \%)$. Specific details of each reaction and the characterization data of the complexes are given below.

\section{$\left[\mathrm{Dy}_{2}\left(\mathrm{LH}_{2}\right)(\mathrm{LH})\left(\mathrm{CH}_{3} \mathrm{OH}\right)\left(\mathrm{N}_{3}\right)\right] \cdot 2 \mathrm{H}_{2} \mathrm{O}(\mathbf{1})$}

Quantities: $\mathrm{LH}_{4}(0.040 \mathrm{~g}, 0.11 \mathrm{mmol}), \mathrm{DyCl}_{3} \cdot 6 \mathrm{H}_{2} \mathrm{O}(0.041 \mathrm{~g}, 0.11 \mathrm{mmol}), \mathrm{NaN}_{3}(0.010 \mathrm{~g}, 0.15$ mmol), Et ${ }_{3} \mathrm{~N}$ (0.046 mL, $0.33 \mathrm{mmol}$ ). Yield: 0.046 g, 74.07\% (based on the Dy ${ }^{\mathrm{III}}$ salt). Mp: >250 ${ }^{\circ} \mathrm{C}$ (d). IR (KBr) cm-1: 3373 (br), 2963 (br), 2848 (br), 2053.37(s), 2036(s), 1609 (s), 1571 (w), 1554 (s), 1536 (s), 1474 (s), 1442 (w), 1429, 1356 (s), 1263 (w), 1220 (w), 1198 (s), 1149 (s), 1080 (s), 1015 (s), 1010 (w), 883 (s), 850 (s), 796 (w), 759 (s), 709 (w), 691 (s), 595 (s), 532 (s). Anal. Calcd. For $\mathrm{C}_{38} \mathrm{H}_{47} \mathrm{Dy}_{2} \mathrm{~N}_{11} \mathrm{O}_{10}$ (1142.86): C, 38.75; H, 4.13; N, 13.43 Found: C, 39.05; H, 4.55; N, 13.91. ESI-MS m/z, ion: 518.5698, $\left(\mathrm{C}_{36} \mathrm{H}_{40} \mathrm{Dy}_{2} \mathrm{~N}_{8} \mathrm{O}_{8}\right)^{2+}$

\section{$\left[\mathrm{Y}_{2}\left(\mathrm{LH}_{2}\right)(\mathrm{LH})\left(\mathrm{CH}_{3} \mathrm{OH}\right)\left(\mathrm{N}_{3}\right)\right] \cdot 2 \mathrm{H}_{2} \mathrm{O}\left(\mathbf{1}_{\mathrm{Y}}\right)$}

Quantities: $\mathrm{LH}_{4}(0.040 \mathrm{~g}, 0.11 \mathrm{mmol}), \mathrm{YCl}_{3} \cdot 6 \mathrm{H}_{2} \mathrm{O}(0.0338 \mathrm{~g}, 0.11 \mathrm{mmol}), \mathrm{NaN}_{3}(0.010 \mathrm{~g}, 0.15$ mmol), Et $3 \mathrm{~N}$ (0.046 mL, 0.33 mmol). Yield: 0.041 g, 73.74\% IR (KBr) cm ${ }^{-1}: 3342$ (br), 2036.35 (s), 1610.78 (s), 1571 (w), 1556.33 (s), 1475 (s), 1357.42 (s), 1199 (s), 1079 (s), 851 (s), 760 (s). Anal. Calcd. For $\mathrm{C}_{37} \mathrm{H}_{47} \mathrm{Y}_{2} \mathrm{~N}_{11} \mathrm{O}_{11}$ (999.15): C, 44.76; H, 4.74; N, 15.41 Found: C, 45.17; H, 4.95; N, 15.89.

\section{$5 \%$ Diluted analogue of $1(15 \%)$}

Quantities: $\mathrm{LH}_{4}(0.040 \mathrm{~g}, 0.11 \mathrm{mmol}), \mathrm{DyCl}_{3} \cdot 6 \mathrm{H}_{2} \mathrm{O}(0.0021 \mathrm{~g}, 0.005 \mathrm{mmol}), \mathrm{YCl}_{3} \cdot 6 \mathrm{H}_{2} \mathrm{O}(0.0321 \mathrm{~g}$, $0.105 \mathrm{mmol}), \mathrm{NaN}_{3}(0.010 \mathrm{~g}, 0.15 \mathrm{mmol}), \mathrm{Et}_{3} \mathrm{~N}(0.046 \mathrm{~mL}, 0.33 \mathrm{mmol}) . \mathrm{IR}(\mathrm{KBr}) \mathrm{cm}^{-1}: 3341$ (br),

\section{ACCEPTED MANUSCRIPT}


2854 (br), 2036.29(s),1610 (s), 1571 (w), 1536 (s), 1474 (s), 1444 (w), 1357 (s), 1263 (w), 1198

(s), 1149 (s), 1078 (s), 1015 (s), 851 (s), 759 (s).

\section{$\left[\mathrm{Tb}_{2}\left(\mathrm{LH}_{2}\right)(\mathrm{LH})\left(\mathrm{CH}_{3} \mathrm{OH}\right)\left(\mathrm{N}_{3}\right)\right] \cdot \mathrm{H}_{2} \mathrm{O} \cdot \mathrm{MeOH}(2)$}

Quantities: $\mathrm{LH}_{4}(0.040 \mathrm{~g}, 0.11 \mathrm{mmol}), \mathrm{TbCl}_{3} \cdot 6 \mathrm{H}_{2} \mathrm{O}(0.041 \mathrm{~g}, 0.11 \mathrm{mmol}), \mathrm{NaN}_{3}(0.01 \mathrm{~g}, 0.15$ mmol), $\mathrm{Et}_{3} \mathrm{~N}$ (0.046 mL, $0.33 \mathrm{mmol}$ ). Yield: $0.035 \mathrm{~g}, 55.2 \%$ (based on the $\mathrm{Tb}^{\mathrm{III}}$ salt). Mp: $>250$ ${ }^{\circ} \mathrm{C}$ (d). IR (KBr) cm-1: 3342 (br), 2960 (br), 2909 (br), 2036 (s), 1610 (s), 1554 (w), 1536 (w), 1474 (s), 1442 (w), 1359 (s), 1262 (w), 1221 (w), 1198 (s), 1129 (w), 1078 (s), 1015 (s), 904 (w), $884(w), 850($ s), $816(w), 776(w), 759($ s), $711(w), 691(w), 630(w), 595(w), 535(s)$. Anal. Calcd. For $\mathrm{C}_{38} \mathrm{H}_{49} \mathrm{~Tb}_{2} \mathrm{~N}_{11} \mathrm{O}_{11}$ (1153.73): C, 39.56; H, 4.28; N, 13.35 Found: C, 39.97; H, 4.73; N, 13.89. . ESI-MS m/z, ion: 515.0687, $\left(\mathrm{C}_{36} \mathrm{H}_{40} \mathrm{~Tb}_{2} \mathrm{~N}_{8} \mathrm{O}_{8}\right)^{2+}$.

\section{Results and Discussion}

\section{Synthetic Aspects}

Polyfunctional ligands have been used with a great deal of efficacy to assemble various complexes containing lanthanide ions. Among such multi-dentate ligands aroylhydrazone-based Schiff base ligands are particularly versatile because of several features including their flexibility involving C-C bond rotation and the potential of utilizing either the enolate or the keto forms of the ligand to bind to the metal ion. ${ }^{11 d, 11 f,}{ }^{31}$ Harnessing these features, previously we have assembled dinuclear lanthanide complexes (Scheme S2). ${ }^{11 \mathrm{~d}}$

Motivated by the above results, we have designed and synthesized 6-((bis(2-hydroxyethyl)amino)$N^{\prime}$-(2-hydroxybenzylidene)picolinohydrazide $\left(\mathrm{LH}_{4}\right)$. The latter was prepared by following a fivestep synthetic protocol (Scheme S1).

\section{ACCEPTED MANUSCRIPT}


The ligand $\mathrm{LH}_{4}$ contains seven coordination sites which can be partitioned into two unsymmetrical pockets, a tridentate pocket comprising of a phenolic oxygen, an imine $\mathrm{N}$, and hydrazine $\mathrm{O}$ $(2 \mathrm{O}, 1 \mathrm{~N})$ while the other is pentadentate, consisting of a pyridine $\mathrm{N}$, a common hydrazone oxygen `and a diethanolamine motif (2N, 3O). The observed coordination behavior would depend also on the extent of deprotonation and can be summarized in the following way. If double deprotonation occurs the ligand would exist in the enol form, $\left[\mathrm{LH}_{2}\right]^{2-}$. On the other hand, if triple deprotonation were to occur, where one arm of diethanolammine is deprotonated, $[\mathrm{LH}]^{3-}$ (enol form) would result. In fact in the formation of the dinuclear complexes discussed herein, both $\left[\mathrm{LH}_{2}\right]^{2-}$ and $[\mathrm{LH}]^{3-}$ are involved (Scheme 1). 

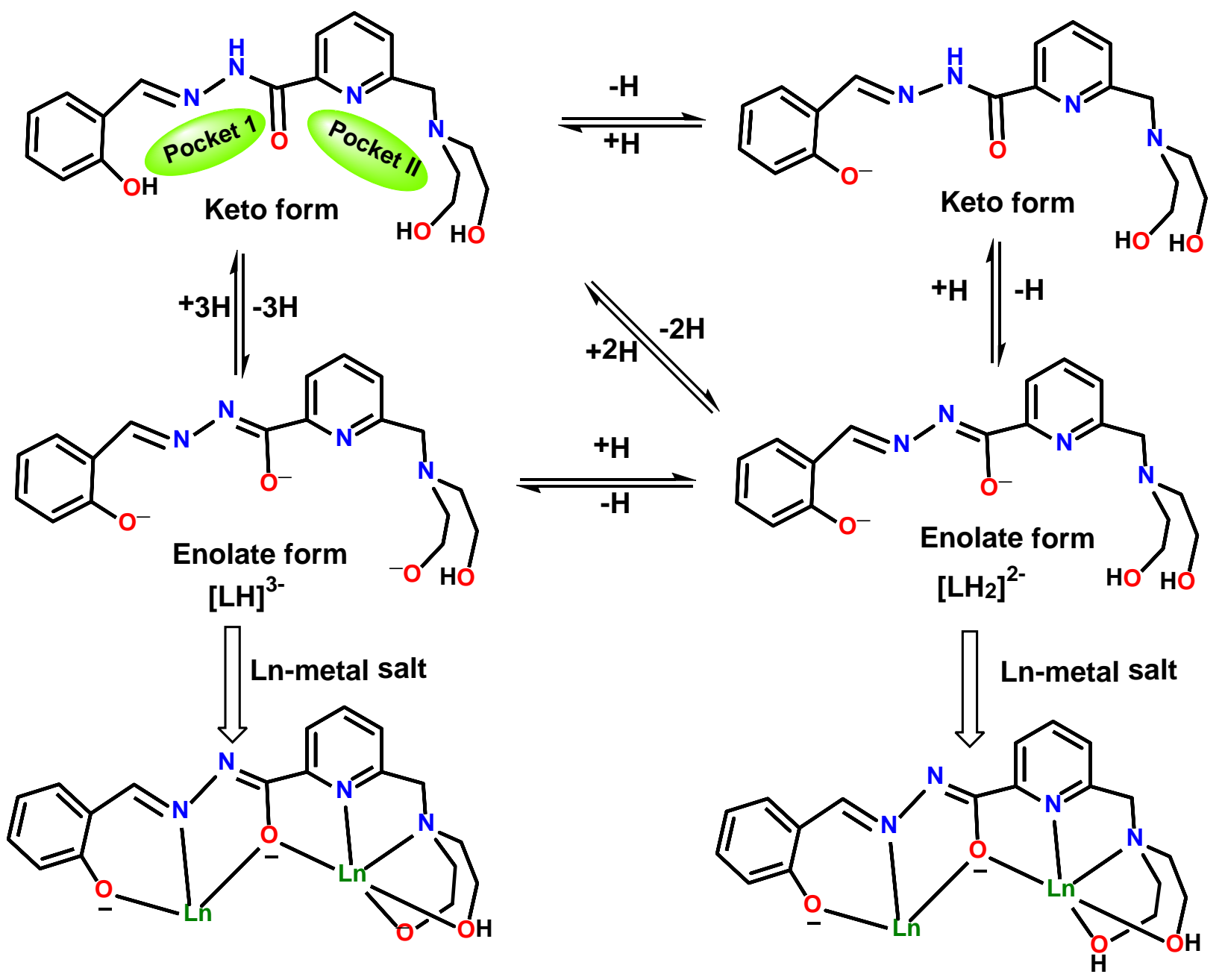

Scheme 1. $\mathrm{LH}_{4}$ showing unsymmetrical coordination pockets, various conformations based on base-assisted reversible keto-enol tautomerization and coordination modes.

In addition to using the ligand $\mathrm{LH}_{4}$ we have used sodium azide as the co-ligand with the intention of exploring the coordination capability of the azide ion. We anticipated a bridging coordination role for the azide ligand. However, as described below, because of the competing bridging coordination of the enolate form the ligand, the azide takes up a terminal position. Thus, the reaction of $\mathrm{LH}_{4}, \mathrm{LnCl}_{3} \cdot 6 \mathrm{H}_{2} \mathrm{O}$ and sodium azide in the presence of triethylamine in a molar ratio of 
1:1:1:3 afforded dinuclear complexes, $\left[\mathrm{Ln}_{2}\left(\mathrm{LH}_{2}\right)(\mathrm{LH})\left(\mathrm{CH}_{3} \mathrm{OH}\right)\left(\mathrm{N}_{3}\right)\right] \cdot \mathrm{xMeOH} \cdot \mathrm{yH}_{2} \mathrm{O}[\mathbf{1}$, $\mathrm{Ln}=$ Dy $\left.{ }^{\mathrm{III}}, \mathrm{x}=0, \mathrm{y}=2 ; 2, \mathrm{Ln}=\mathrm{Tb}^{\mathrm{III}}, \mathrm{x}=0, \mathrm{y}=2\right]$ (Scheme 2).

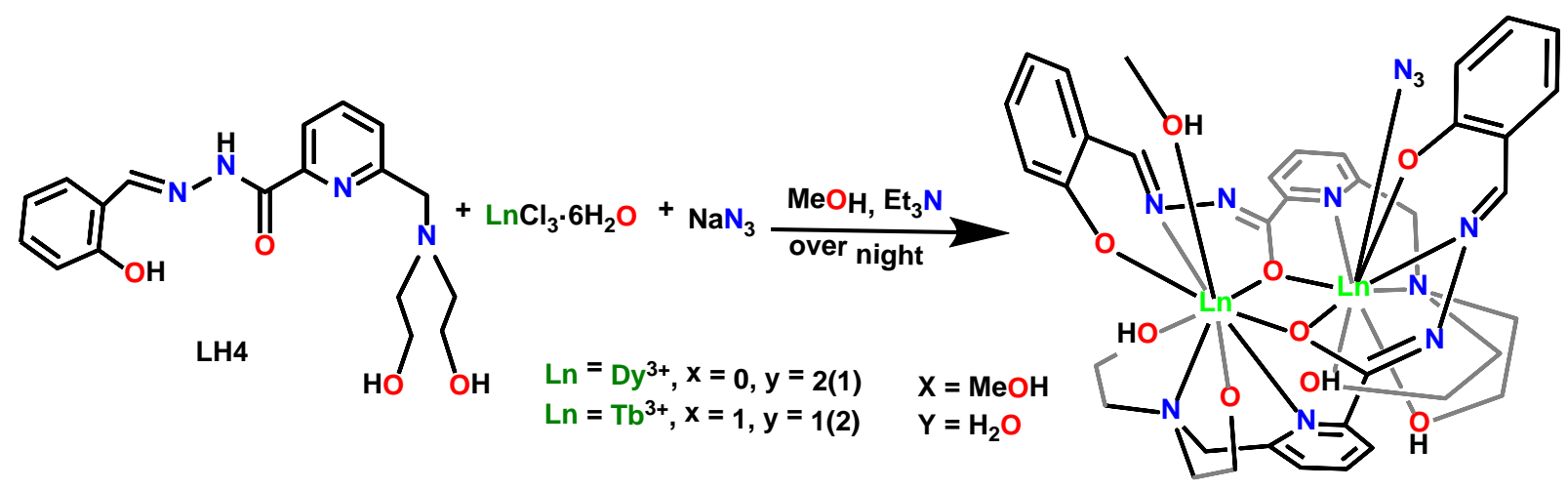

Scheme 2. Synthesis of $\mathrm{Ln}_{2}$ complexes 1-2.

In order to check the phase purity of the complexes, powder X-ray diffraction measurement for complexes was done and found that the sequence and pattern of the peaks are in reasonable agreement with the simulated data obtained from single-crystal data (Figures S1, S2).

We have carried out ESI-MS studies to check the structural integrity of these complexes in solution. These studies reveal peaks at $m / z=518.5698$ and 515.0687 for $\mathbf{1}, 2$ respectively, corresponding to the species $\left[\mathrm{Dy}_{2}\left(\mathrm{LH}_{2}\right)(\mathrm{LH}) \mathrm{H}\right]^{2+},\left[\mathrm{Tb}_{2}\left(\mathrm{LH}_{2}\right)(\mathrm{LH}) \mathrm{H}\right]^{2+}$. This indicates that these complexes remain partially intact in solution.The ESI-MS spectra of complexes are given in the Supporting Information (Figures S3 and S4).

\section{X-ray Crystallography}


Suitable single crystals of the complexes 1-2 were obtained by slow evaporation of their solutions in methanol/chloroform mixture (1:1) within a week. Single crystal X-ray diffraction study reveals that the complexes 1-2 are isostructural and charge neutral. These crystallize in a monoclinic system $(C 2 / c$ with $\mathrm{Z}=8)$ Since $\mathbf{1}$ and $\mathbf{2}$ are isostructural we describe the molecular structure of $\mathbf{1}$ as a representative example. A perspective view of $\mathbf{1}$ is given in Figure 1 and that of complex $\mathbf{2}$ is given in the Supporting Information (Figures S5 ). Selected bond lengths and bond angles of $\mathbf{1}$ are given in Table 2 while those of $\mathbf{2}$ are given in Table S2.

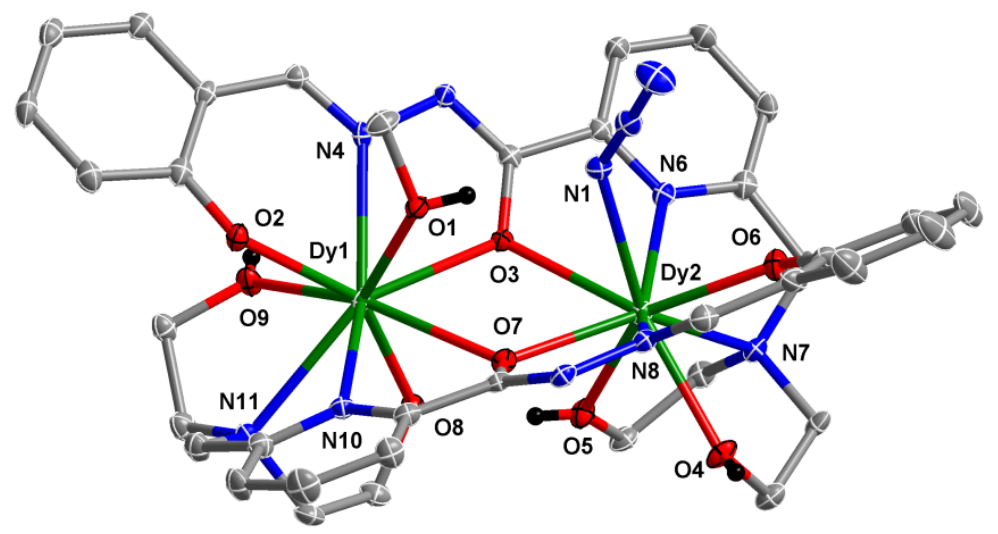

(a)

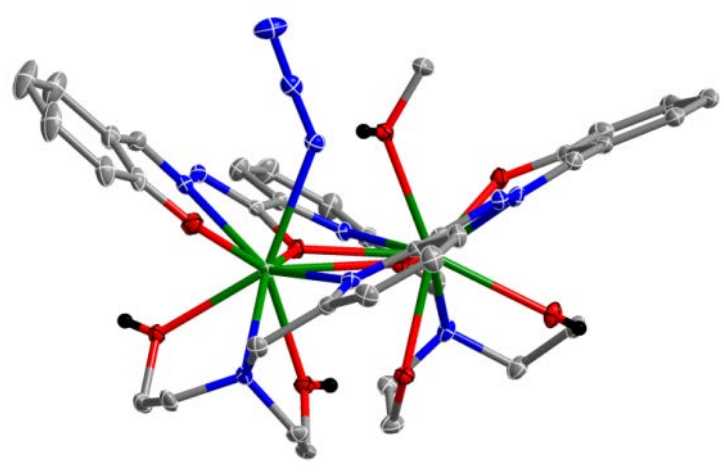

(b)

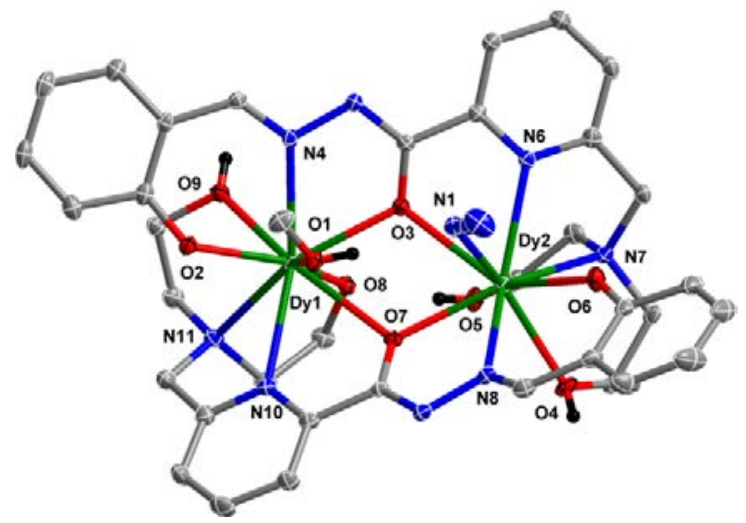

(c) 
Figure 1. (a) Molecular structure of 1, (b) and (c) side- and top view of $\mathbf{1}$. Thermal ellipsoids at 50\% probability level are shown (selected hydrogen atoms and the solvent molecules have been omitted for clarity). Color codes: $\mathrm{N}=$ blue; $\mathrm{O}=$ red; $\mathrm{C}=$ grey; $\mathrm{Dy}=$ dark green and $\mathrm{H}=$ black)

Table 2. Selected bond distance $(\AA)$ and bond angles $\left({ }^{\circ}\right)$ of $\mathbf{1}$

\begin{tabular}{|ll|lr|ll|}
\hline \multicolumn{2}{|l|}{ Bond distances around Dy1 } & \multicolumn{3}{l|}{ Bond distances around Dy2 } & \multicolumn{2}{l|}{ Bond angles around Dy } \\
Dy(1)-O(7) & $2.557(17)$ & Dy(2)-O(7) & $2.341(17)$ & Dy(1)-O(3)-Dy(2) & $115.80(7)$ \\
Dy(1)-O(8) & $2.312(17)$ & Dy(2)-O(3) & $2.516(17)$ & Dy(1)-O(7)-Dy(2) & $114.87(7)$ \\
Dy(1)-O(3) & $2.359(17)$ & Dy(2)-O(5) & $2.376(19)$ & \\
Dy(1)-O(9) & $2.526(19)$ & Dy(2)-O(4) & $2.404(18)$ & \\
Dy(1)-O(2) & $2.234(17)$ & Dy(2)-O(6) & $2.217(18)$ & \\
Dy(1)-O(1) & $2.492(19)$ & Dy(2)-N(6) & $2.487(2)$ & \\
Dy(1)-N(11) & $2.628(2)$ & Dy(2)-N(8) & $2.516(2)$ & \\
Dy(1)-N(10) & $2.525(2)$ & Dy(2)-N(7) & $2.636(2)$ & \\
Dy(1)-N(4) & $2.512(2)$ & Dy(2)-N(1) & $2.544(2)$ & \\
& & & & \\
\hline
\end{tabular}

The molecular structure of 1 consists of two Dy ${ }^{\mathrm{III}}$ ions, a di anionic ligand [ $\left.\mathrm{LH}_{2}\right]^{2-}$, a trianionic ligand $[\mathrm{LH}]^{3-}$, an azide anion and a neutral methanol giving an overall neutral dinuclear assembly. Interestingly, the two lanthanide ions present in the assembly are non-equivalent as described below. The $\left[\mathrm{LH}_{2}\right]^{2-}$ and $[\mathrm{LH}]^{3-}$ ligands encapsulate the two Dy ${ }^{\mathrm{III}}$ ions in a "head-to-tail" manner utilizing their two coordination pockets, a tridentate $\mathrm{P} 1(\mathrm{O}, 2 \mathrm{~N})$ and a pentadentate $\mathrm{P} 2(3 \mathrm{O}, 2 \mathrm{~N})$ unit to generate the dimeric $\left[\mathrm{Dy}_{2}\left(\mathrm{LH}_{2}\right)(\mathrm{LH})\right]^{+}$motif (Figure 1 and Scheme 1). Note that in the formation of $\mathbf{1}$, the ligand has exclusively utilized the enol form to generate the $\mathrm{Dy}_{2} \mathrm{O}_{2}$ core. The enolate oxygen atoms (O3 and O7) of the ligand bridge the two metal centers affording a quadrilateral four-membered $\mathrm{Dy}_{2} \mathrm{O}_{2}$ core as deduced from the bond distances, Dy1-O3 = $2.359 \AA$, Dy1-O7 = $2.557 \AA$, Dy2-O3 = $2.516 \AA$ and Dy2-O7 = 2.341 $\AA$. (Figure 2). The Dy $\cdots$ Dy distance and the two Dy-O-Dy angles in the central $\mathrm{Dy}_{2} \mathrm{O}_{2}$ cores are found to be $4.131 \AA$ and $115.80(7)$, 
114.87(7) respectively. Because of the bridging coordination of the enolate form of the ligand, we believe that the azide ligand is forced to function as a terminal ligand to one of the lanthanide centers. On the other lanthanide center the ninth coordination is provided by a neutral methanol. Overall, the dinuclear assembly contains two types of nine-coordinated Dy ${ }^{\mathrm{III}}$ centers; Dy1 (coordination environment, 3N, 6O), Dy2 (coordination environment, 4N, 5O).

In order to ascertain if other mono anions such as chloride would similarly bind in a monodentate fashion, we carried out the reaction using $\mathrm{DyCl}_{3} \cdot 6 \mathrm{H}_{2} \mathrm{O}$ as the starting material but in the absence of the additional azide ligand. Under these conditions, however, we were not able to isolate any pure crystalline products.

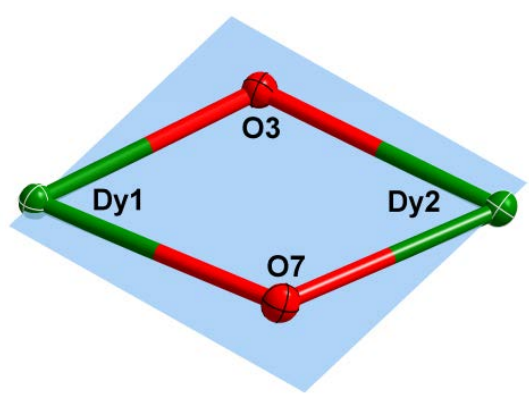

(a)

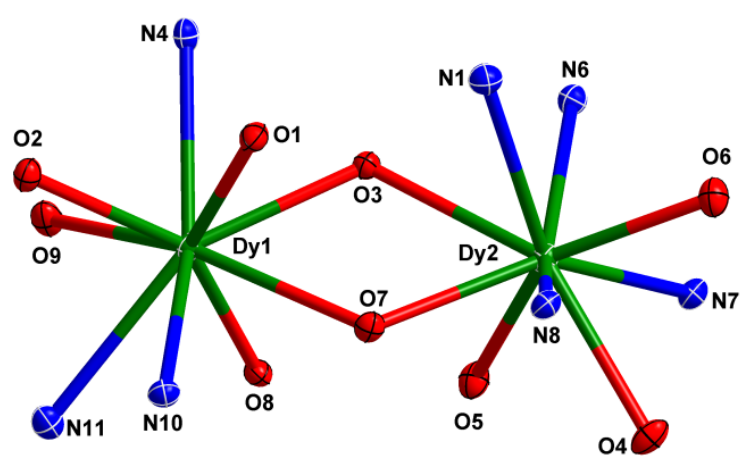

(b)

Figure 2. a) Quadrilateral $\mathrm{Dy}_{2} \mathrm{O}_{2}$ core of $\mathbf{1}$; b) core structure of $\mathbf{1}$. The outer backbone of the ligands are omitted for clarity.

As alluded above, 1 contains two different types of Dy ${ }^{\text {III }}$ centres. While both the Dy1 and Dy2 are nine-coordinated they are non-equivalent because they are surrounded by slightly different coordination environments. Dy1 is bound by the deprotonated arm of the diethanolamine of ligand $[\mathrm{LH}]^{3-}$ with the ninth coordination provided by neutral methanol while Dy2 is bound by the neutral diethanolamine arm of $\left[\mathrm{LH}_{2}\right]^{2-}$ with the ninth coordination provided by the azide ligand. The ligand

\section{ACCEPTED MANUSCRIPT}


in this assembly binds in two ways, one as $\left[\mathrm{LH}_{2}\right]^{2-}$ and the other as $[\mathrm{LH}]^{3-}$. In the latter, one of the diethanolamine arm is deprotonated. The bond lengths found in the deprotoated arm $\left(-\mathrm{CH}_{2}-\mathrm{CH}_{2}-\right.$ $\mathrm{O}(\mathrm{O} 8)$ are consistent with literature precedents. ${ }^{11 \mathrm{f}}$ SHAPE analysis reveals that the coordination geometry around Dy1 and Dy2 (and other analogues) can be described as spherical capped square antiprism (Figure 3, Table S4). ${ }^{32}$

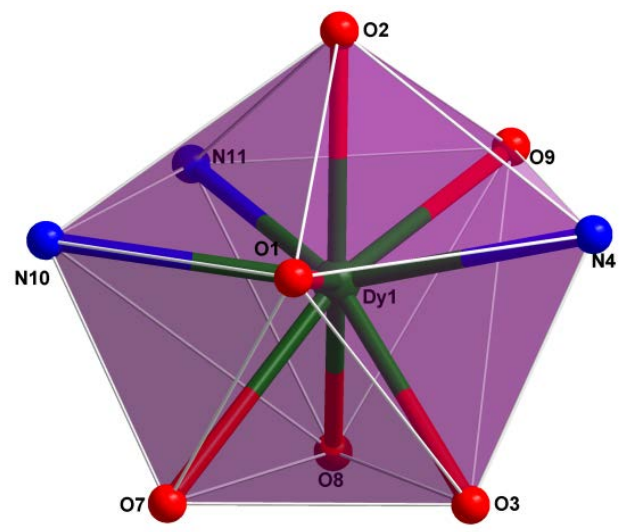

(a)

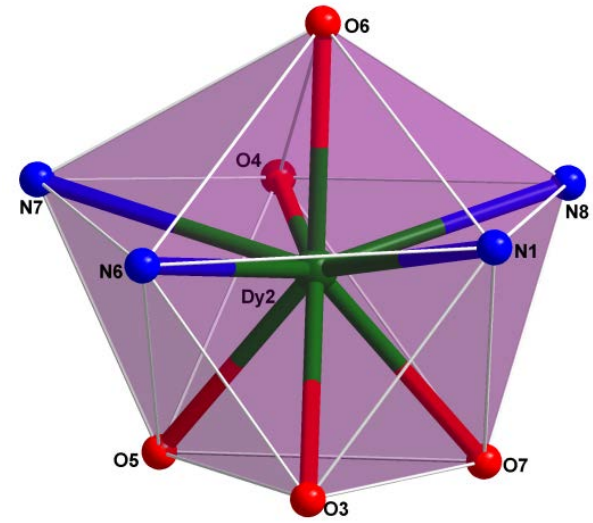

(b)

Figure 3. Spherical capped square antiprism coordination geometry around Dy1 (a) and Dy2 (b).

The Dy-O bond lengths fall in a range, 2.217-2.557 $\AA$. The Dy- $\mathrm{O}_{\text {methanol }}(2.492 \AA)$ bond length is slightly longer than those observed previously ${ }^{31}$, 33 The deprotonated Dy-Odiethanolamine (O8) (2.312 $\AA$ ) bond length is slightly longer than that observed in the literature, but smaller than the bond length onvolving the nuetral diethanolamine arm. ${ }^{11 f}$ All the Dy-N bond lengths fall in a very narrow range, $2.487-2.636 \AA$, consistent with values found in the literature. ${ }^{31}$ The bond angles, Dy1-O3-Dy2 and Dy1-O7-Dy2 are $115.80^{\circ}$ and $117.86^{\circ}$ respectively (Figure 2 and Table 2 ). The crystal structure of $\mathbf{1}$ reveals the presence of intra- and intermolecular hydrogen bonds leading to the formation of a 1D polymeric chain(Figure S7-8). 


\section{Magnetic Studies}

Static magnetic properties: $d c$ magnetic properties of the two complexes $\mathbf{1}$ and $\mathbf{2}$ were determined by measuring the thermal dependence of the molar magnetic susceptibility $\left(\chi_{\mathrm{M}}\right)$ from 2 to $300 \mathrm{~K}$ (Figure 4). The room temperature values of the $\chi_{\mathrm{M}} \mathrm{T}$ product are $27.90 \mathrm{~cm}^{3} \mathrm{~K} \mathrm{~mol}^{-1}$ and $22.42 \mathrm{~cm}^{3}$ $\mathrm{K} \mathrm{mol}^{-1}$, close to the expected values of $28.34 \mathrm{~cm}^{3} \mathrm{~K} \mathrm{~mol}^{-1}$, and $23.64 \mathrm{~cm}^{3} \mathrm{~K} \mathrm{~mol}^{-1}$,respectively for two isolated Dy ${ }^{\mathrm{III}}$ ions $\left({ }^{6} H_{15 / 2}\right.$ and $\left.g_{\mathrm{J}}=4 / 3\right)$ and $\mathrm{Tb}^{\mathrm{III}}\left({ }^{7} F_{6}\right.$ and $\left.g_{\mathrm{J}}=3 / 2\right) .{ }^{34}$ On cooling, $\chi \mathrm{MT}$ of $\mathbf{1}$ monotonously decreases down to $25 \mathrm{~K}$, temperature for which a plateau is almost observed, and then decreases progressively reaching a minimum of $23.60 \mathrm{~cm}^{3} \mathrm{~K} \mathrm{~mol}^{-1}$ at $2 \mathrm{~K}$. The $\chi_{\mathrm{MT}}$ of 2 remains almost constant down to $75 \mathrm{~K}$ then decreases to reach the value of $20.68 \mathrm{~cm}^{3} \mathrm{~K} \mathrm{~mol}^{-1}$ at 8 $\mathrm{K}$ and finally slightly increases at very low temperature $\left(20.88 \mathrm{~cm}^{3} \mathrm{~K} \mathrm{~mol}^{-1}\right.$ at $\left.2 \mathrm{~K}\right)$. For both compounds 1 and 2, the decrease can be mainly attributed to the depopulation of the ligand-field levels, while the change of slope at a lower temperature than $25 \mathrm{~K}$ could be due to the existence of weak magnetic interactions.

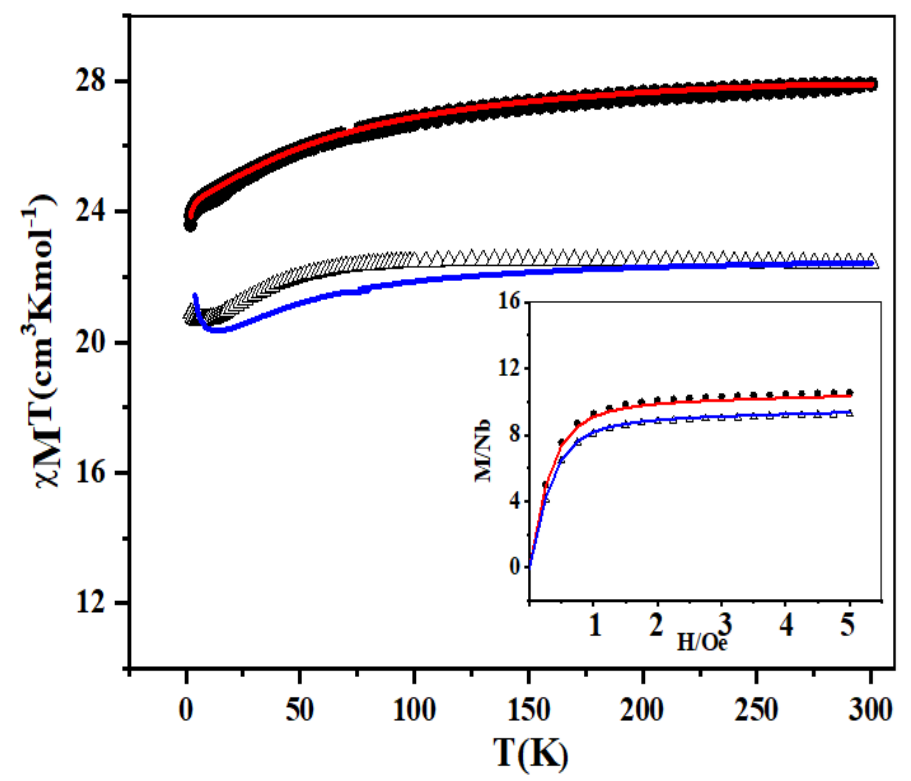


Figure 4. Thermal dependence of the $\chi \mathrm{MT}$ product for $\mathbf{1}$ (full black circles), $\mathbf{2}$ (open triangles). Red and blue lines correspond to the best simulated curves from POLY_ANISO program implemented in MOLCAS 8.2 package for complex $\mathbf{1}$ and 2. M vs $\mathrm{H}$ plot at 2K is fitted and given in inset.

The field dependence of the magnetization has been measured for different temperatures from 2 to $5 \mathrm{~K}$. At $2 \mathrm{~K}$, these show a classic behavior with values of $10.54 \mathrm{~N} \beta$ and $9.26 \mathrm{~N} \beta$ respectively for two Dy ${ }^{\mathrm{III}}$ ions with the presence of a magnetically anisotropic ground state and two $\mathrm{Tb}^{\mathrm{III}}$ ions (inset of Figure 4). Furthermore, the absence of a superposition in the different M vs. H curves for each system (Figure S9), elucidates the presence of significant magnetic anisotropy for $\mathbf{1}$ and $\mathbf{2}$, as well as the possibility of low-lying excites states in the systems.

Dynamic magnetic properties. ac measurements have been performed for $\mathbf{1}$ and $\mathbf{2}$. At zero $d c$ magnetic field $\mathbf{1}$ displays a frequency dependence of the magnetic susceptibility in the temperature range of 2-15 $\mathrm{K}$ in the window 1-1000 Hz frequency of the oscillating field (Figure 5a and S10). The relaxation time $(\tau)$ has been extracted with an extended Debye model ${ }^{35}$ (see SI, Figure S11, Table S6). The Argand plot confirms that the observed slow magnetic relaxation corresponds to the entire sample (Figure S12). The corresponding thermal variation of the $\log (\tau)$ is depicted in Figure $5 \mathrm{~d}$ and clearly shows a linear dependence (Orbach process) in the temperature range of 7$11 \mathrm{~K}$ while a deviation from the linearity is observed down to $6 \mathrm{~K}$ due to the presence of underbarrier processes such as Raman and Quantum Tunnelling of the Magnetization (QTM). It is well known that the latter can be cancelled by applying a $d c$ magnetic field. ${ }^{36 a}$, $36 \mathrm{~b}$ Thus, the field dependence of the magnetic susceptibility at $2 \mathrm{~K}$ (Figure S13) shows an optimal behaviour at a

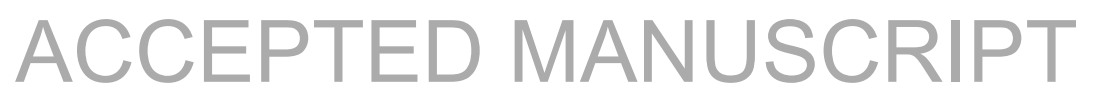


selected dc magnetic field value of 800 Oe (Figure 5b and Table S7). At $2 \mathrm{~K}$ and zero applied $d c$ field, $\chi_{M}$ " $v s . v$ curve passes through a maximum at $5 \mathrm{~Hz}$ which is shifted to $1 \mathrm{~Hz}$ upon applying a 800 Oe magnetic field (Figure 5c and S14) because of the removal of the QTM contribution.
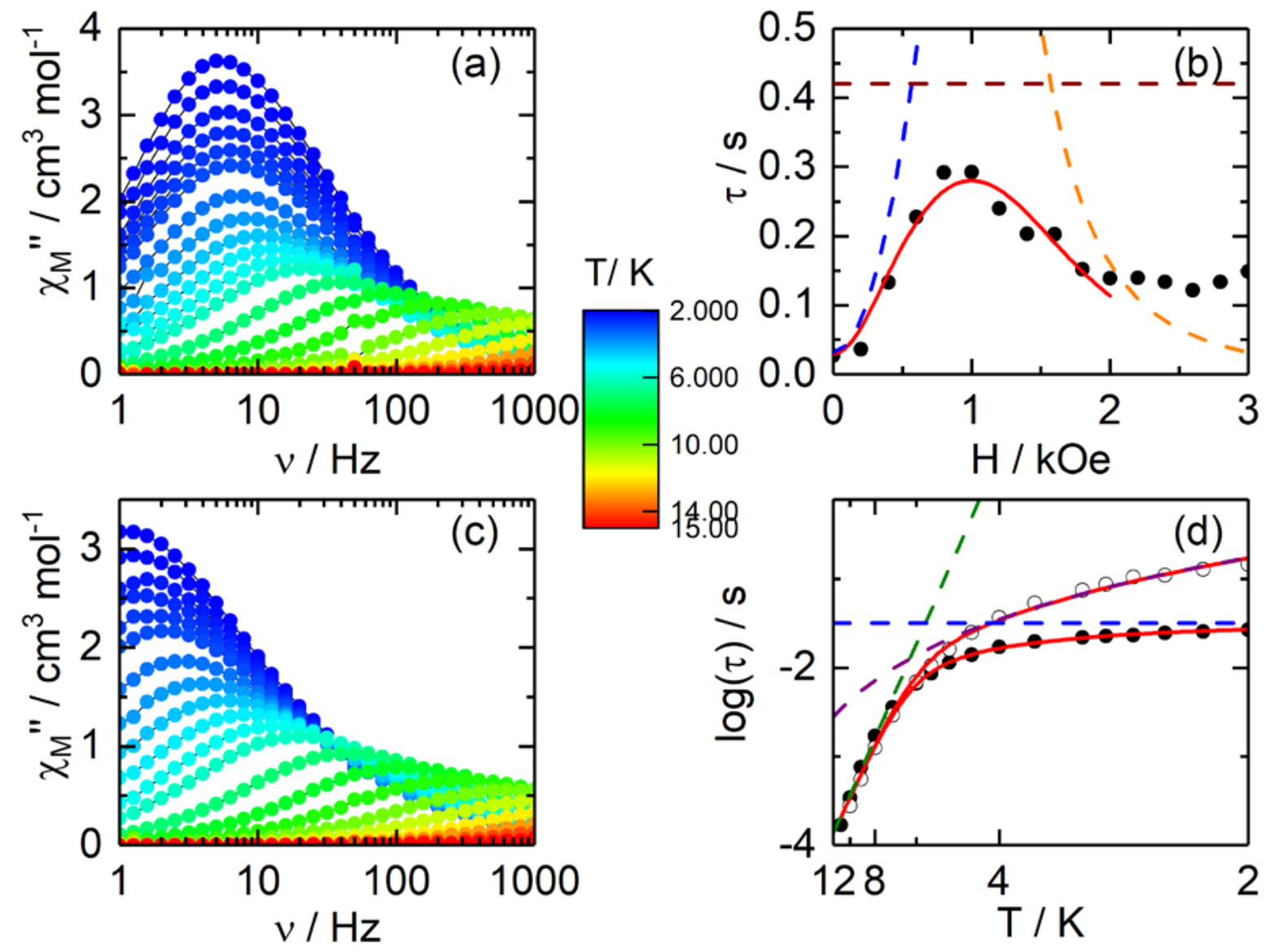

Figure 5. a) Out-of-phase component of the $a c$ magnetic susceptibility data for $\mathbf{1}$ in zero field in the temperature range of 2-15 K, b) field dependence of the magnetic relaxation time at $2 \mathrm{~K}$ in the field range of 0-3000 Oe with the full red line is the best-fitted curves (see text) while the dashed lines are the Orbach/Raman (brown), QTM (blue) and Direct (orange) contributions, c) Out-ofphase component of the $a c$ magnetic susceptibility data for $\mathbf{1}$ in 800 Oe in the temperature range of 2-15 $\mathrm{K}$ and d) thermal dependence of the magnetic relaxation time for $\mathbf{1}$ in zero (full black circles) in the 2-11 K temperature range and 800 Oe (open circles) applied magnetic field in the 2- 
$10 \mathrm{~K}$ temperature range. Full lines are the best-fitted curves (see text) while the dashed lines are the Orbach (green), Raman (purple) and QTM (blue) contributions.

The relaxation time $(\tau)$ has been extracted with the extended Debye model (Table S7) and the corresponding relaxation time of the magnetization in the temperature range of 2-11 $\mathrm{K}$ are given in Figure 5d, corresponding again to a general behavior of the sample as seen in the Argand plot (Figure S15). As for $\mathbf{1}$ in zero field, the linear region depicted in the temperature dependence of the magnetic relaxation time has deviated at the lower temperatures, which is a sign of a remained contribution of under energy barrier processes. At the optimal field of 800 Oe, the involvement of a significant Direct process or remaining QTM can be discarded. To support this affirmation, the $\tau v$ s. $H$ curve was fitted with the equation 1 for the 0 -2000 Oe field range (Figure 6b). ${ }^{36 c, 36 d}$

$$
\tau^{-1}=\frac{B_{1}}{1+B_{2} H^{2}}+2 B_{3} H^{m}+B_{4} \quad \text { Eq. } 1
$$

With the three terms correspond respectively to the QTM, Direct and field-independent magnetic relaxation processes (Raman and Orbach). The best fit was obtained for $\mathrm{B}_{1}=31.25 \mathrm{~s}^{-1} ; \mathrm{B}_{2}=$ $3.795(10) \times 10^{-5} \mathrm{Oe}^{-2} ; \mathrm{B}_{3}=1.95(4) \times 10^{-13} \mathrm{~s}^{-1} \mathrm{~K}^{-1} \mathrm{Oe}^{-4}$ and $\mathrm{B}_{4}=2.38(4) \mathrm{s}^{-1}$ leading to $\tau^{-1}(\mathrm{QTM})=$ $1.23 \mathrm{~s}^{-1}$ (blue contribution on Figure $5 \mathrm{~b}$ ), $\tau^{-1}$ (Direct) $=0.16 \mathrm{~s}^{-1}$ (orange contribution on Figure $5 \mathrm{~b}$ ) and $\tau^{-1}($ Raman + Orbach $)=2.38 \mathrm{~s}^{-1}$ (brown contribution on Figure $\left.5 \mathrm{~b}\right)$. Thus, the thermal variation of the magnetic relaxation times could be fitted using a combination of Orbach and Raman processes. Since these two processes are field independent (equation 2), they can be considered constant for both relaxation time at 0 Oe and 800 Oe.

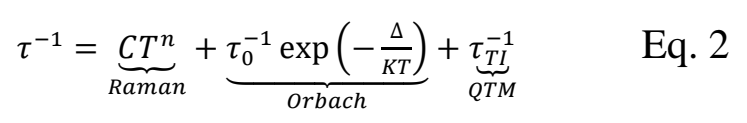


Indeed, the thermal variation of the relaxation time is simultaneously fitted for $\mathbf{1}$ in zero and 800 Oe field with Orbach ( $\Delta$ and $\tau_{0}$ ) and Raman ( $C$ and $n$ ) shared parameters while QTM ( $\left.\tau_{T \mathrm{TI}}\right)$ appears only at 0 Oe. The best fitted curves are represented on Figure $5 \mathrm{~d}$ with $\Delta=59(3) \mathrm{K}, \tau_{0}=10(4) \times 10^{-}$ ${ }^{6} \mathrm{~s}, C=1.2(2) \mathrm{K}^{-\mathrm{n}} \mathrm{s}^{-1}, n=2.3(1)$ and $\tau_{\Gamma \mathrm{II}}=0.032(2) \mathrm{s}$. Importantly, $\tau_{\mathrm{\Gamma I}}$ fitted from thermal variation matches the zero field limit of Eq. $1\left(\mathrm{~B}_{1}^{-1}\right)$ obtained from field variations. The expected $\mathrm{n}$ value for Kramers ions should be $9,{ }^{37}$ but it is well known that for molecular systems, ${ }^{38}$ the presence of both acoustic and optical phonons could lead to lower values comprised between 2 and $7 .^{39}$ A search in the literature reveals that Dy-based dimers show a most common coordination number $8^{8,10}$, and more recently the tendency tries to go to low coordination systems ${ }^{8 h}$. However, very few unsymmetric Dy-based dimers have been reported. ${ }^{8 a, 10 d, 110 e, ~ 40 a-g}$ The properties found in such complexes are consistent with the results found in this work. These results are summarized in Table $3{ }^{8 \mathrm{a}, 10 \mathrm{~d}, 110 \mathrm{e}, 40 \mathrm{a}-\mathrm{g}}$ If one considers a similar coordination geometry, viz., the spherical capped square antiprism geometry, examples with field-induced relaxation are known. ${ }^{41}$ In the present instance, however, we have observed zero field SMM behavior.

Table 3. Some representative examples of dinuclear dysprosium complexes with unsymmertrical coordination environment.

\begin{tabular}{|l|c|c|l|}
\hline \multicolumn{1}{|c|}{ Compound } & $\begin{array}{c}\text { Local } \\
\text { geometries } \\
\text { around } \mathrm{Ln}^{\text {III }} \\
\text { centers }\end{array}$ & Magnetic properties & ref. \\
\hline$\left[\mathrm{Dy}_{2} \mathrm{Ovph}_{2} \mathrm{Cl}_{2}(\mathrm{MeOH})_{3}\right] 3 \mathrm{MeCN}$ & $\begin{array}{c}\text { Hula hoop-like } \\
\text { geometry(centre } \\
\text { 1) and } \\
\text { pentagonal }\end{array}$ & $\begin{array}{c}U_{\text {eff }}=150 \mathrm{~K} \\
\tau_{0}=2.3 \times 10^{-10} ; \\
\text { and } U_{\text {eff }}=198 \mathrm{~K}\end{array}$ & [8a] \\
\hline
\end{tabular}




\begin{tabular}{|c|c|c|c|}
\hline $\begin{array}{l}\mathrm{H}_{2} \mathrm{Ovph}=\text { pyridine-2-carboxylic acid [( } 2 \text { - } \\
\text { hydroxy-3-methoxyphenyl)methylene] } \\
\text { hydrazide) }\end{array}$ & $\begin{array}{l}\text { bypyramidal(cen } \\
\text { tre } 2)\end{array}$ & $\tau_{0}=7.3 \times 10^{-9}$ & \\
\hline $\begin{array}{l}{[\mathrm{hqH} 2]\left[\mathrm{Dy}_{2}(\mathrm{hq})_{4}\left(\mathrm{NO}_{3}\right)_{3}\right] \mathrm{MeOH}} \\
\text { 8-hydroxyquinoline }(\mathrm{hqH})\end{array}$ & $\begin{array}{l}\text { Bicapped } \\
\text { trigonal prism } \\
\text { geometry }\end{array}$ & $\begin{aligned} \text { Field induced SMM } \\
\underbrace{}_{\text {eff }}=41 \mathrm{~cm}^{-1} \\
\tau_{0}=1.4 \times 10^{-6} \mathrm{~s}\end{aligned}$ & [10d] \\
\hline $\begin{array}{l}{[(\mu \text {-mbpymNO)- }\{(\mathrm{tmh}) 3 \mathrm{Dy}\} 2]} \\
\text { (tmh = 2,2,6,6-tetramethyl-3,5- heptanedionate } \\
\text { mbpymNO = Bipyrimidine-N-Oxide }\end{array}$ & $\begin{array}{l}\text { Triangular } \\
\text { dodecahedron } \\
\text { and } \\
\text { square- } \\
\text { antiprismatic }\end{array}$ & $\begin{array}{c}\text { SMM } \\
U_{\text {eff }}=54.7 \mathrm{~K} \\
\tau_{0}=1.7(3) \times 10^{-9} ; \\
\text { and } U_{\text {eff }}=47.8 \mathrm{~K} \\
\tau_{0}=1.5(4) \times 10^{-9} \mathrm{~S}\end{array}$ & [10e] \\
\hline $\begin{array}{l}{\left[\left[\mathrm{Dy}\left(\mathrm{Cy}{ }_{3} \mathrm{PO}\right)_{2}-\right.\right.} \\
\left.(\mu-\mathrm{Br})(\mathrm{Br})_{2}\right]_{2} 2 \mathrm{C}_{7} \mathrm{H}_{8} \\
\left(\mathrm{Cy} y_{3} \mathrm{PO}=\text { tricyclohexylphosphine oxide }\right)\end{array}$ & $\begin{array}{c}\text { Distorted } \\
\text { octahedral }\end{array}$ & $\begin{array}{c}\text { SMM } \\
U_{\text {eff }}=684.1 \mathrm{~K} \\
\tau_{0}=3.84 \times 10^{-12} \mathrm{~s} .\end{array}$ & {$[40 \mathrm{a}]$} \\
\hline $\begin{array}{l}{\left[\left[\mathrm{Dy}\left(\mathrm{Cy}{ }_{3} \mathrm{PO}\right)_{2}-\right.\right.} \\
\left.(\mu-\mathrm{I})(\mathrm{I})_{2}\right]_{2} 4 \mathrm{C}_{7} \mathrm{H}_{8} \\
\text { (Сy3 } \mathrm{PO}=\text { tricyclohexylphosphine oxide) })\end{array}$ & $\begin{array}{l}\text { Distorted } \\
\text { octahedral }\end{array}$ & $\begin{array}{c}\text { SMM } \\
U_{\text {eff }}=1290 \mathrm{~K} \\
\tau_{0}=1.26 \times 10^{-12} \mathrm{~S}\end{array}$ & [40b] \\
\hline $\begin{array}{l}{\left[\mathrm{Dy}_{2}(\mathrm{Hhmb})_{3}(\mathrm{NCS})_{3}\right] \cdot 2 \mathrm{MeOH} \cdot \mathrm{py}} \\
\left(\mathrm{H} 2 \mathrm{hmb}=\mathrm{N}^{\prime}-(2-h y d r o x y-3-\right. \\
\text { methoxybenzylidene)- } \\
\text { benzhydrazide) }\end{array}$ & $\begin{array}{c}\text { Monocapped } \\
\text { distorted square } \\
\text { antiprismatic } \\
\text { geometry }\end{array}$ & $\begin{array}{c}\text { Field induced SMM } \\
U_{\text {eff }}=2.4 \mathrm{~K} \\
\tau_{0}=0.16 \mathrm{~s}\end{array}$ & [40c] \\
\hline $\begin{array}{l}{\left[\mathrm{Dy}_{2}(\mathrm{~L} 1)_{2}(\mathrm{acac})_{2}\left(\mathrm{H}_{2} \mathrm{O}\right)\right] \cdot 2 \mathrm{CH}_{2} \mathrm{Cl}_{2}} \\
\mathrm{~L}_{1}=N, N \text {-bis(salicylidene)-o-phenylenediamine }\end{array}$ & $\begin{array}{l}\text { Distorted } \\
\text { square antiprism } \\
\text { and capped } \\
\text { trigonal prism }\end{array}$ & $\begin{array}{c}\text { SMM } \\
U_{\text {eff }}=36 \mathrm{~K} \\
\tau_{0}=4.2 \times 10^{-7} ; \\
\text { and } U_{\text {eff }}=80 \mathrm{~K} \\
\tau_{0}=8.3 \times 10^{-8} \mathrm{~s} .\end{array}$ & [40d] \\
\hline $\begin{array}{l}{\left[\mathrm{Dy}_{2}(\mathrm{~L} 1)_{2}(\mathrm{DBM})_{2}\left(\mathrm{H}_{2} \mathrm{O}\right)\right] \cdot 2 \mathrm{CH}_{2} \mathrm{Cl}_{2}} \\
\mathrm{~L}_{1}=N, N \text {-bis(salicylidene)-o- } \\
\text { phenylenediamine, } \\
\text { DBM = dibenzoylmethane }\end{array}$ & $\begin{array}{l}\text { Distorted square } \\
\text { antiprism and } \\
\text { capped trigonal } \\
\text { prism }\end{array}$ & $\begin{array}{c}\text { SMM } \\
U_{\text {eff }}=31.4 \mathrm{~K} \\
\tau_{0}=6.6 \times 10^{-7} ; \\
\text { and } U_{\text {eff }}=59.6 \mathrm{~K} \\
\tau_{0}=7.3 \times 10^{-8} \mathrm{~S}\end{array}$ & {$[40 \mathrm{e}]$} \\
\hline $\begin{array}{l}{\left[\mathrm{Dy}_{2} \mathrm{~L}_{2}(\mathrm{HL})\left(\mathrm{NO}_{3}\right)(\mathrm{EtOH})\right] \cdot 0.5 \mathrm{C}_{2} \mathrm{H}_{5} \mathrm{OH}} \\
\left(\mathrm{LH}_{2}=5 \text {-chloro-2-(((2-hydroxy-3- }\right. \\
\text { methoxybenzyl)imino)methyl) phenol) }\end{array}$ & $\begin{array}{l}\text { triangular } \\
\text { dodecahedron } \\
\text { and square } \\
\text { antiprism }\end{array}$ & $\begin{array}{c}\text { SMM } \\
U_{\text {eff }}=69.19 \mathrm{~K} \\
\tau_{0}=9.5 \times 10^{-6} ; \\
\text { and } U_{\text {eff }}=45.73 \mathrm{~K} \\
\tau_{0}=4.6 \times 10^{-6} \mathrm{~S} \\
\end{array}$ & [40f] \\
\hline $\begin{array}{l}\left(\mathrm{HNEt}_{3}\right)\left[\mathrm{Dy}_{2}(\mathrm{MQ})_{4}\left(\mathrm{NO}_{3}\right)_{3}\right] \cdot \mathrm{EtOH} \cdot \mathrm{H}_{2} \mathrm{O} \\
(\mathrm{HMQ}=2 \text {-methyl-8-hydroxyquinoline })\end{array}$ & $\begin{array}{c}\text { Square } \\
\text { antiprism and } \\
\text { spherical } \\
\text { tricapped } \\
\text { trigonal prism, }\end{array}$ & $\begin{array}{l}\text { Slow relaxation of } \\
\text { magnetization }\end{array}$ & {$[40 \mathrm{~g}]$} \\
\hline$\left[\mathrm{Dy}_{2}\left(\mathrm{LH}_{2}\right)(\mathrm{LH})\left(\mathrm{CH}_{3} \mathrm{OH}\right)\left(\mathrm{N}_{3}\right)\right] \cdot 2 \mathrm{H}_{2} \mathrm{O}$ & $\begin{array}{l}\text { Capped square } \\
\text { antiprismatic } \\
\text { geometry }\end{array}$ & $\begin{array}{c}\text { SMM } \\
U_{\text {eff }}=59(3) \mathrm{K} \\
\tau_{0}=10(4) \times 10^{-6} \mathrm{~s}\end{array}$ & $\begin{array}{l}\text { This } \\
\text { work }\end{array}$ \\
\hline
\end{tabular}


The molecular structure of $\mathbf{1}$ highlighted two Dy ${ }^{\mathrm{III}}$ ions in different coordination sphere i.e. N3O6 and $\mathrm{N} 4 \mathrm{O} 5$ respectively for the Dy1 and Dy2 surroundings. One could expect two distinct magnetic behavior while it was observed that both Dy ${ }^{\mathrm{III}}$ centers are involved in the magnetic relaxation at the same frequency for a given temperature. The previous published dissymmetrical $\mathrm{Dy}^{\mathrm{III}}$ dinuclear SMMs displayed either single $e^{40 \mathrm{a}-40 \mathrm{~b}}$ or multiple ${ }^{40 \mathrm{~d}-40 \mathrm{~g}}$ relaxation contributions.

The magnetic properties of the diluted $\mathbf{1 5 \%}$ analogue were studied in order to obtain a greater information of the slow relaxation mechanism in such Dy2 SMM, especially to understand the effects of magnetic interactions within the dynamic magnetic properties in the dimer. The field dependence of the magnetization at $2 \mathrm{~K}$ (Figure S16) shows a classic behavior with a value of $0.614 \mathrm{~N} \beta$ at $5 \mathrm{~T}$, confirming a magnetic dilution of approximately 6\%. 15\% display an SMM behavior at zero applied field (Figure 6, S17-18), which is shifted to the higher frequencies (158 $\mathrm{Hz}$ ) compared to $1(5 \mathrm{~Hz})$ at $2 \mathrm{~K}$. Such shift is in agreement with a faster magnetic relaxation time when the magnetic interactions are cancelled by magnetic dilution. 

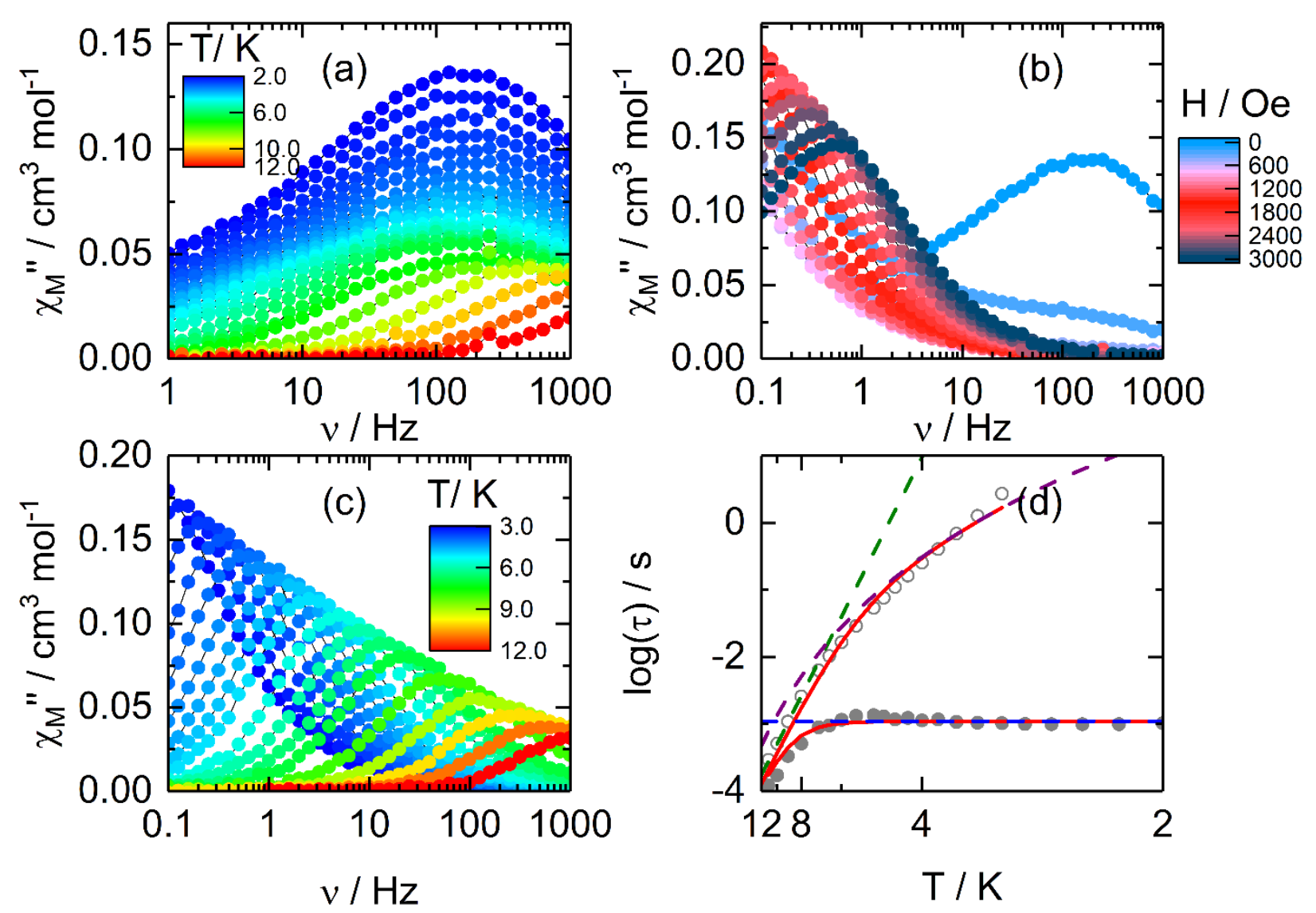

Figure 6. a) Out-of-phase component of the ac magnetic susceptibility data for $\mathbf{1 5 \%}$ in zero field in the temperature range of 2-15 K, b) Out-of-phase component of the ac magnetic susceptibility data for $\mathbf{1 5 \%}$ at $2 \mathrm{~K}$ from 0 to 3000 Oe, c) Out-of-phase component of the ac magnetic susceptibility data for $\mathbf{1}$ in 800 Oe in the temperature range of 2-15 K and d) thermal dependence of the magnetic relaxation time for $\mathbf{1}$ in zero (full grey circles) in the 2-11 K temperature range and 800 Oe (open circles) applied magnetic field in the 2-10 K temperature range. Full lines are the best-fitted curves (see text) while the dashed lines are the Orbach (green), Raman (purple) and QTM (blue) contributions.

As previously, the extended Debye model was used in order to extract the temperature dependence of the relaxation mechanism (Tables S8 and S9) corresponding to a general behavior of the sample (Argand in Figure S15). Again, the thermal variation of the relaxation time is simultaneously fitted 
for zero and 800 Oe field with Orbach parameters ( $\Delta$ and $\tau_{0}$ ), injected from the linear fit at high temperature region (from 8 to $12 \mathrm{~K}$ ) of the in-field relaxation curve (Figure 6d), and Raman ( $C$ and $n$ ) shared parameters while QTM ( $\left.\tau_{\mathrm{TI}}\right)$ appears only at 0 Oe. The best fitted curves are represented on Figure 6d with $\Delta=66(1) \mathrm{K}, \tau_{0}=7.3(8) \times 10^{-7} \mathrm{~s}, C=9(3) \times 10^{-4} \mathrm{~K}^{-\mathrm{n}} \mathrm{s}^{-1}, n=5.9(2)$ and $\tau_{\mathrm{TI}}=1.10(6) \times 10^{-3} \mathrm{~s}$.

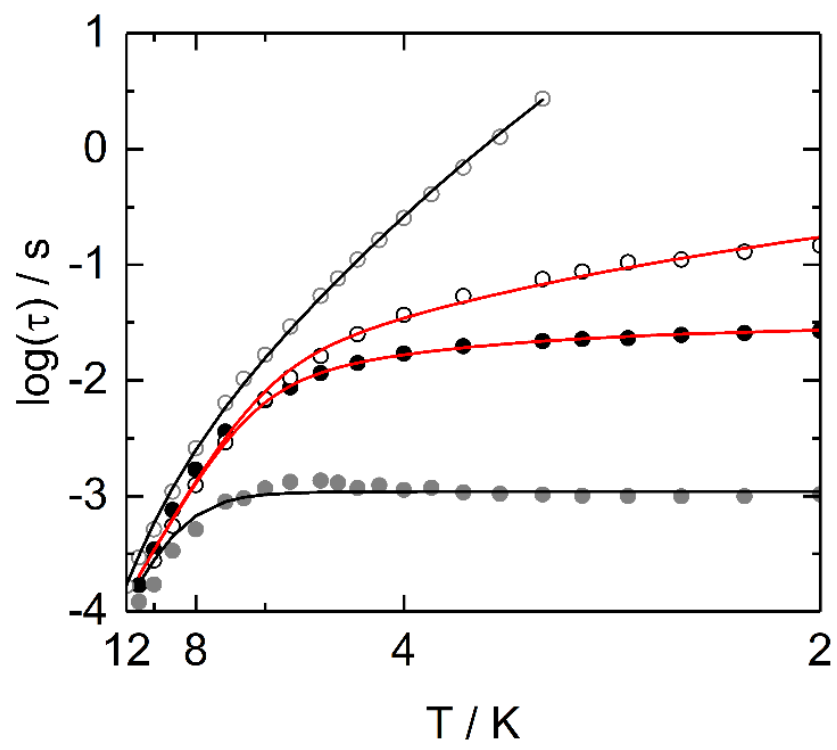

Figure 7. Thermal variation of the relaxation time for $\mathbf{1}$ at $\mathrm{H}=0$ Oe (full black spots) and $\mathrm{H}=800$ Oe (open black circles) and $\mathbf{1 5} \%$ at $\mathrm{H}=0$ Oe (full gray spots) and $\mathrm{H}=800$ Oe (open gray circles). Full red and black lines are the best-fitted curves (see text) for $\mathbf{1}$ and $\mathbf{1 5 \%}$ respectively.

The Figure 7 depicts the four thermal dependence of the relaxation times for $\mathbf{1}$ and $\mathbf{1 5 \%}$. Indeed, at zero applied field, the suppression of the magnetic interactions between magnetic centers by magnetic dilution lead to an increase of the fast relaxation QTM process. However, under an applied magnetic field, the magnetization of the diluted sample relaxed slower than the 
magnetization of $\mathbf{1}$ (Figure 7) because of the decrease of the Raman contribution $(\mathrm{T}<6 \mathrm{~K})$ for $\mathbf{1}_{5 \%}$ compared to 1. Such diminution of the Raman contribution might be attributed to the diamagnetic dilution which reduces the interactions with the matrix. Such trend in the magnetic relaxation time can be reinforced by the behavior of the hysteresis loop of the magnetization of both compounds at $2 \mathrm{~K}$. In which, once an applied magnetic field and the QTM is released, the hysteresis loop for 15\% opens, in opposition to 1 which remains closed (Figure 21).

At zero applied magnetic field, 2 was not displaying any out-of-phase component of the susceptibility at $2 \mathrm{~K}$ in the window $1-1000 \mathrm{~Hz}$ frequency of the oscillating field (Figure S22). Indeed, $\mathbf{2}$ involves non-Kramers $\mathrm{Tb}^{\mathrm{III}}$ ion which requires highly axial symmetric ligand field to possess a bistable ground state and prevent efficient QTM. ${ }^{42}$ In order to cancel the possible QTM, the magnetic susceptibility has been measured under various applied magnetic field (Figure S23). As soon as a $d c$ field is applied, an out-of-phase contribution appears at $30 \mathrm{~Hz}$ which grows with the increase of the applied magnetic field. The 2800 Oe value is selected as the optimal applied magnetic field. At such field, the magnetic susceptibility displays a frequency dependence between 2 and $6 \mathrm{~K}$ (Figure S23) which is an indication of the slow magnetic relaxation for 2 . The thermal dependence of the relaxation time has been plotted selecting by hand the maxima of the out-ofphase signal at each temperature (Figure S24). Considering the weak thermal dependence of the relaxation time and the 2800 Oe applied magnetic field value, one might suggest that the most probable magnetic relaxation occurs via a direct process $\left(\tau^{-1}=\mathrm{AH}^{4} \mathrm{~T}\right)$.

\section{$A b$ initio Calculations}

To investigate and quantify the nature of magnetic relaxations occurring at the individual magnetic centre and for the entire complex, detailed multireference $a b$ initio calculation has been performed for complexes $\mathbf{1}$ and 2. The methodology employed here for the calculation is given in

\section{ACCEPTED MANUSCRIPT}


computational details (see Experimental Section). First, the magnetic properties at the individual magnetic centre have been calculated using the X-ray structures, wherein one of the Tb/Dy centres were replaced by a diamagnetic $\mathrm{Lu}^{\mathrm{III}}$ ion. The calculations were performed on the entire complexes without further modelling.

\section{Mechanism of Magnetic relaxation by Individual $\mathrm{Dy}{ }^{\mathrm{III}} / \mathrm{Tb}^{\mathrm{III}}$ ions}

Single ion calculations at the individual $\mathrm{Ln}^{\mathrm{III}}$ centre shows that the lowest-lying eight Kramer Doublets (KDs) behave differently for both the centres depending on the nature of the terminal coordination environment. For complex 1, the low lying $8 \mathrm{KDs}$ are lying in the range of $176.3 \mathrm{~cm}^{-1}$ to $820.8 \mathrm{~cm}^{-1}$ for Dy1 centre where methanol is coordinated, whereas for Dy2 centre the ground to highest excited state lays in the range of 117.6 to $536.0 \mathrm{~cm}^{-1}$ (Table S12 in SI) where terminal azide coordination is present. Though the splitting of 8 KDs is upto the range of 820.8 and $536.0 \mathrm{~cm}^{-1}$, the relaxation is occuring at the $1^{\text {st }}$ excited state, due to the displacement of the anisotropic axis at the excited state compared to the ground state. The large difference for the two Dy centers is due to the difference in the crystal field effect provided by the two different terminal ligands and their influence on the geometry. ${ }^{43}$ The $\mathrm{MeOH}$ terminal coordination provides stronger axial CF compared to azide coordination. The required crystal field Hamiltonian is described as $H_{C F}=\sum_{k, q} B_{k}^{q} O_{k}^{q}$ where $B_{k}^{q}$ is the crystal-field parameter and $O_{k}^{q}$ is Steven's operator (Table S14). ${ }^{44}$ The axial parameter $B_{k}^{q}$ (where $\mathrm{k}=0$ and $\mathrm{q}=2$ ) is comparatively larger for the Dy1 ion $(-8.98)$ compared to the Dy2 site (-2.35). This is in agreement with our computed low lying energy splitting for the lowest eight doublets. To further understand the difference between electronic effects induced by the $\mathrm{MeOH} v s$ azide and geometric effects caused by the same, we performed additional calculations on model systems $\mathbf{1 a}$ and $\mathbf{1 b}$. Here model $\mathbf{1 a}$ represents a structure where

\section{ACCEPTED MANUSCRIPT}


both Dy1 and Dy2 are coordinated to the methanol while model $\mathbf{1 b}$ represents a structure where both the Dy ${ }^{\mathrm{III}}$ centres are coordinated to an azide group. The energy splitting obtained for both the models 1a ( for 1a-Dy1 185.4 to $829.8 \mathrm{~cm}^{-1}$, 1a-Dy2 137.5 to $630.9 \mathrm{~cm}^{-1}$ ) and $\mathbf{1 b}$ (for 1b-Dy1 178.5 to $823.5 \mathrm{~cm}^{-1}$, 1b-Dy2 131.5 to $675 \mathrm{~cm}^{-1}$ ) are similar to the original structures (see SI, Table S12). This unequivocally reveals that the geometric effects due to the substitution play a prominent role in dictating the anisotropy and not the individual $\mathrm{MeOH}$ vs azide electronic effects. The analysis of Loprop charges also arrives at the same conclusion. As the differences lie in the geometry, we looked at the SHAPE analysis, and this reveals that Dy1 has a CShM value 1.432 while Dy2 has 0.905 with respect to ideal nine coordinate Muffine (MFF-9) geometry. Thus, stronger deviation from MFF-9 in Dy1 yields larger anisotropy compared to Dy2.

Further, to understand the magnetic relaxation contributed by the single Dy ${ }^{\mathrm{III}}$ centre, we have looked into the nature of the ground state for both the Dy ${ }^{\mathrm{III}}$ centres. The ground state for Dy1 is of pure $m_{J}= \pm 15 / 2$ in nature, whereas for Dy2, a strong mixing of $m_{J}= \pm 15 / 2$ with other excited states is noticed. The $U_{\text {cal }}$ values obtained for both the centres is $176.3 \mathrm{~cm}^{-1}$ and $117.6 \mathrm{~cm}^{-1}$ respectively. The calculated energy barrier for magnetic relaxations is overestimated compared to the experimental $U_{\text {eff }}$ value. This suggests that the exchange interaction present between the Dy ${ }^{\text {III.....Dy }}{ }^{\text {III }}$ centre/other under-barrier process/QTM effects alters the barrier height for magnetization reversal, hence we looked at the exchange-coupled state of $\{\mathrm{Dy} 2\}$ dimer. Though the nature of anisotropy at the ground level is Ising in nature ( Table 4) for both Dy1 and Dy2 centres, the angle of deviation of the ground state axis (Figure 8) significantly deviates at the first excited state for Dy2 $\left(\sim 7^{\circ} v s . \sim 49^{\circ}\right)$. The combination angle of deviation of the anisotropic axis and the contribution of higher excited state wave functions lead to different magnetic relaxations offered by Dy2.

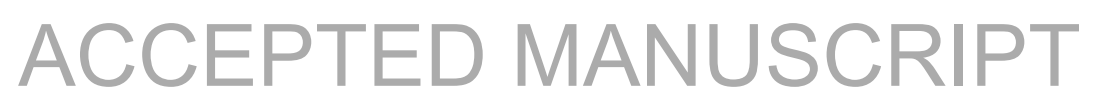


Table 4. Ab initio estimated $g$-values along with the ground state wave function estimated for $\mathbf{1}$ and their respective models.

\begin{tabular}{|l|l|l|l|l|}
\hline Complex & $g_{\mathrm{x}}$ & $g_{\mathrm{y}}$ & $g_{\mathrm{z}}$ & Wave functions contributions to the ground state \\
\hline 1-Dy1 & 0.0106 & 0.0171 & 19.9194 & $0.99| \pm 15 / 2\rangle$ \\
\hline 1-Dy2 & 0.0124 & 0.0199 & 19.7092 & $0.70| \pm 15 / 2\rangle+0.02| \pm 13 / 2\rangle+.20| \pm 11 / 2\rangle+0.04| \pm 9 / 2\rangle$ \\
\hline 1a-Dy1 & 0.0083 & 0.0132 & 19.9226 & $0.99| \pm 15 / 2\rangle$ \\
\hline 1a-Dy2 & 0.0176 & 0.0280 & 19.7353 & $0.96| \pm 15 / 2\rangle\rangle+0.03| \pm 11 / 2\rangle$ \\
\hline 1b-Dy1 & 0.0097 & 0.0162 & 19.9138 & $0.99| \pm 15 / 2\rangle$ \\
\hline 1b-Dy2 & 0.0271 & 0.0476 & 19.7406 & $0.96| \pm 15 / 2\rangle\rangle+0.03| \pm 11 / 2\rangle$ \\
\hline
\end{tabular}
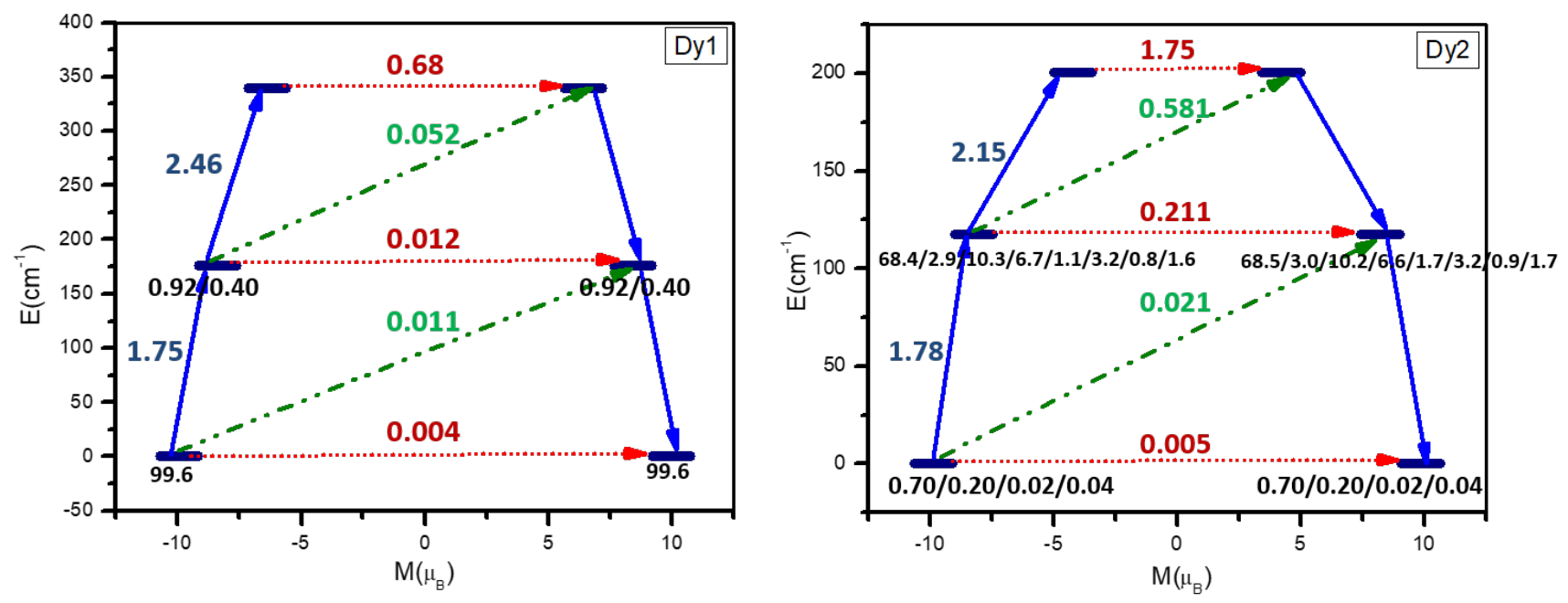

Figure 8. The SINGLE_ANISO calculated relaxation pathways for Dy1 and Dy2 for complex 1. The red line represents the QTM, blue line for TA and green line represents the Orbach/Raman processes. The dark blue(smaller) line indicates the KDs as a function of magnetic moments.The number above these lines represents the transition probabilities from one $m_{\mathrm{J}}$ level to the other $m_{\mathrm{J}}$ level. 


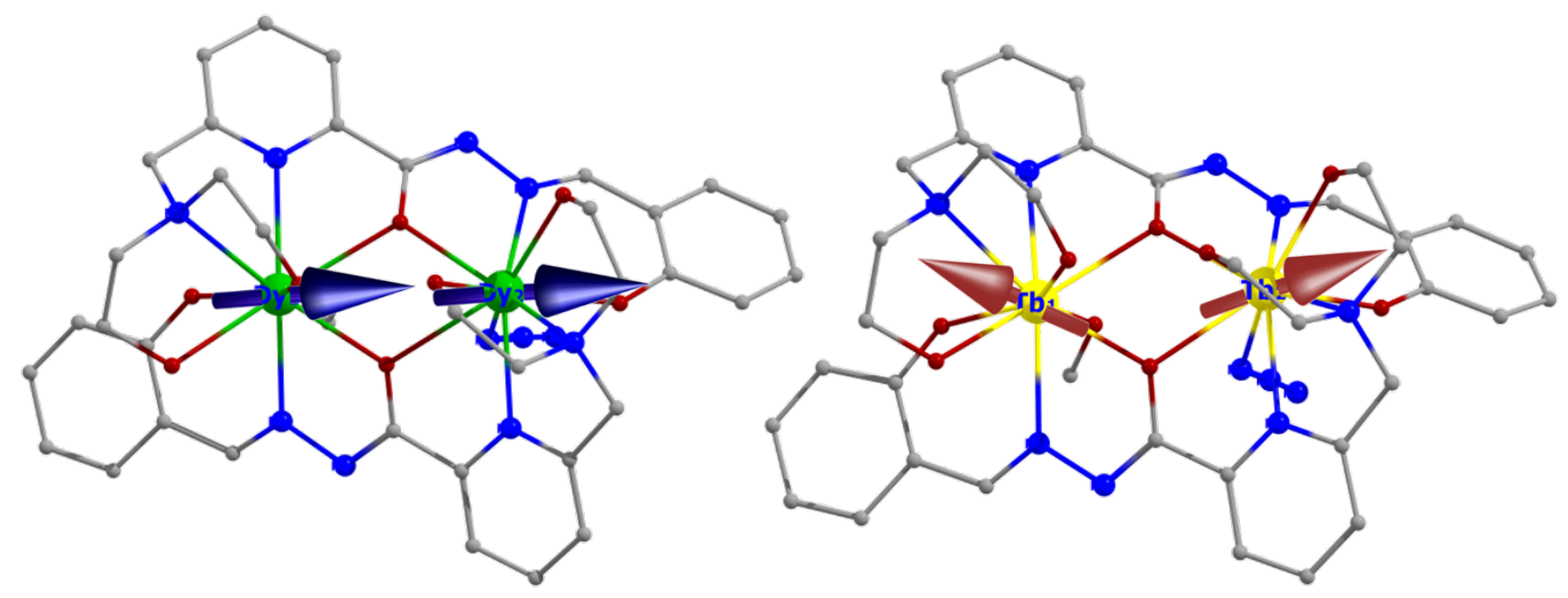

Figure 9. Arrangement of ground state anisotropy axes for complexes $\mathbf{1}$ and 2.

For complex 2, the energy spectrum for the lowest Ising doublets is in the range of 0.3 to 535.5 $\mathrm{cm}^{-1}$ and 0.4 to $408.6 \mathrm{~cm}^{-1}$ respectively for Tb1 and Tb2 centres. Despite having significant ground state anisotropy, the non-Kramer nature of the $\mathrm{Tb}^{\mathrm{III}}$ ion leads to a significant tunnel splitting and lack of zero field SMM behavior for complex 2. The tunnel splitting was found to be $0.19 \mathrm{~cm}^{-1}$ and $0.15 \mathrm{~cm}^{-1}$ for Tb1 and Tb2 centres respectively as a result of different crystal field effects (see Table S13 in SI). The ground state anisotropic axis was plotted for both the complexes $\mathbf{1}$ and $\mathbf{2}$ in Figure 9. The anisotropic axis for complex 1 lies parallel to each other in the same plane, which 
agrees well with the earlier reported Dy2 SMMs. ${ }^{8 \text { a, } 8 \mathrm{~h}}$ In contrast, for complex 2, a significant tilt between the $g_{\mathrm{zz}}$ axis noticed.

Table 5: $A b$ initio and DFT computed exchange values for complex 1-3.

\begin{tabular}{|l|l|l|l|l|}
\hline \multirow{2}{*}{ Complexes } & \multicolumn{2}{l|}{ Ab initio fitted $\left(\mathrm{in}^{-1}\right)$} & DFT computed $\left(\right.$ in $\left.\mathrm{cm}^{-1}\right)$ \\
\cline { 2 - 5 } & $J_{\mathrm{ex}}$ & $J_{\text {dip }}$ & $J_{\mathrm{tot}}$ & $J$ \\
\hline $\mathbf{1}$ & -0.60 & +0.15 & -0.45 & -0.55 \\
\hline $\mathbf{2}$ & +0.45 & +0.13 & +0.58 & +0.60 \\
\hline $\mathbf{3}$ & - & - & - & +0.10 \\
\hline
\end{tabular}

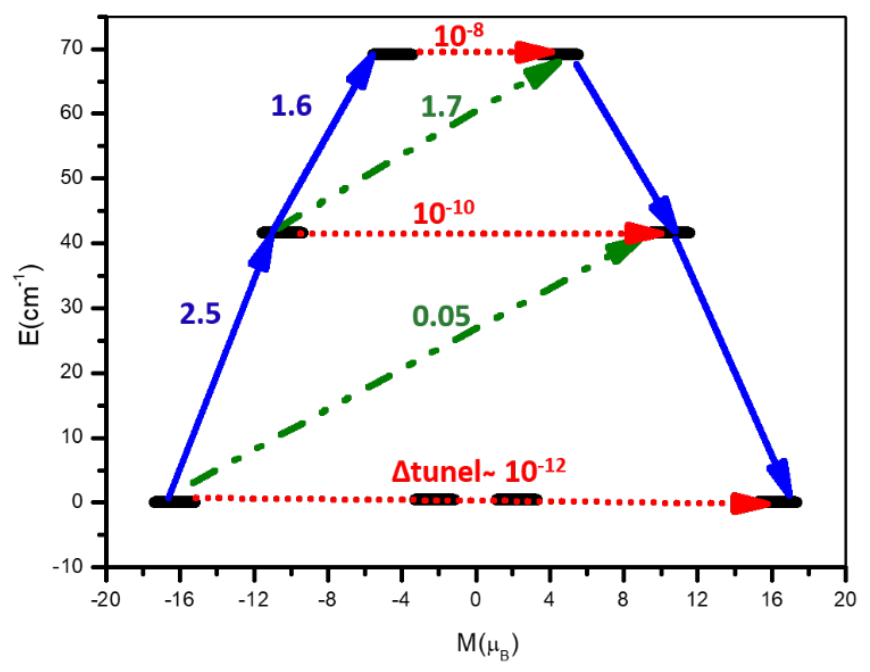

Figure 10: POLY_ANISO derived magnetic relaxation pathways for complex 1. The red line represents the QTM, blue line for TA and green line represents the Orbach/Raman processes. The black line indicates the KDs as a function of magnetic moments. The number above these lines represents the transition probabilities from one $m_{\mathrm{J}}$ level to the other $\mathrm{m}_{\mathrm{J}}$ level. 


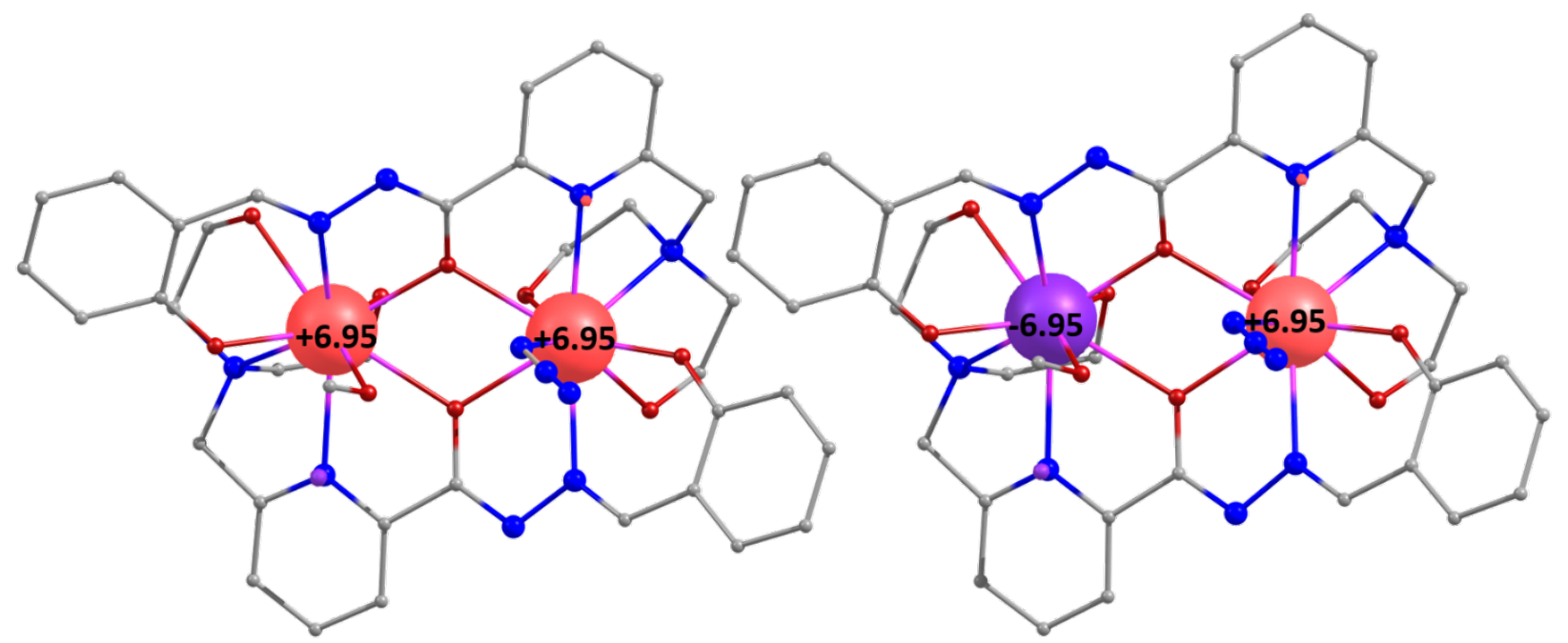

Figure 11. DFT computed spin density plot for complex 3 , the Gd ${ }^{\mathrm{III}}$ analogue of complex $\mathbf{1}$ obtained from broken symmetry calculations, $\alpha$ and $\beta$ densities are represented by red and violet lobe respectively.

\section{Mechanism of Magnetic Relaxation of Exchange Coupled State of 1 and 2:}

For the dinuclear exchanged coupled state, the magnetic relaxation dynamics diagram for complex $\mathbf{1}$ is plotted in Figure 10 using POLY_ANISO calculations. ${ }^{45}$ For complexes $\mathbf{1}$ and 2, both the dipolar and exchange interactions were taken into account by using the Lines model using the Hamiltonian given in equation (3) below. ${ }^{46}$

Following Hamiltonian below is used for calculating the dipolar and exchange interaction between the $\operatorname{Ln}^{\mathrm{III}} \cdot \ldots \cdot \mathrm{Ln}^{\mathrm{III}}$ centres.

$\widehat{H}_{e x}=-\sum_{i} J_{i} S_{i} S_{i+1}$ 
Here $J_{i}=J_{\text {idip }}+J_{\text {iexch }}$; that is, $J_{\mathrm{i}}$ are the total magnetic interaction $\mathrm{Ln}^{\mathrm{III}} \cdots \cdot \mathrm{Ln}^{\mathrm{III}}$, this describes the interaction between the neighbouring metal centres.

$$
\begin{aligned}
& \widehat{H}=-\left(-J_{d i p}^{L n^{i}-L n^{i+1}}+J_{\text {exch }}^{L n^{i}-L n^{i+1}}\right) \tilde{s}_{L n_{i}} \tilde{s}_{L n_{i+1}} \\
& J_{d i p}^{L n^{i}-L n^{i+1}}=\frac{\mu_{B}^{2}}{R_{D y^{i}-D y^{i+1}}^{3}} g_{L n}^{2}
\end{aligned}
$$

Lines model yields an excellent fit with the experimental data, and the extracted $J$ values are given in Table 5. It has been noticed that the exchange interaction between Dy ${ }^{\mathrm{III}} \cdot \ldots \mathrm{Dy}^{\mathrm{III}}$ is weakly antiferromagnetic in nature, whereas for complex 2 , the interaction between $\mathrm{Tb}^{\mathrm{III}} \cdot{ }^{\mathrm{N}} \mathrm{Tb}^{\mathrm{III}}$ is found to ferromagnetic in nature. The mechanism of magnetisation relaxation developed for the dinuclear model is shown in Figure 10. The mechanism computing using the POLY_ANISO routine yields a $U_{\text {cal }}$ value of $69 \mathrm{~cm}^{-1}$ and this matches closely with experimental $U_{\text {eff }}$ value $\left(41 \mathrm{~cm}^{-1}\right)$. It has been observed that there is a discrepancy in the $U_{\text {eff }}$ value obtained by experiment and $U_{\text {cal }}$ value obatained from ab initio calculation for the exchange coupled state. Recently we have reported an alternate equation to estimate the Ucal values for dinuclear Dy ${ }^{\mathrm{III}}$ systems. ${ }^{47}$ The equation is given as follows.

$U_{\text {caleff }}=\left[\frac{U_{\text {cal1 }}}{(Q T M \text { or } T A-Q T M) \times 10^{3}}+\frac{U_{\text {cal1 }}}{(Q T M \text { or } T A-Q T M) \times 10^{3}}\right]+15 J$ (equation 6)

Here $U_{\text {cal1 }}$ and $U_{\text {cal2 }}$ represent the calculated energy barrier for Dy1 and Dy2 center respectively, QTM or TA-QTM represents the value of transition propbabilities between ground states or excited state (one level below where the relaxation is happening). These values are taken from Figure 8 and Table S12 of SI. Using the above formula the $U_{\text {caleff }}$ is now estimated to be $59 \mathrm{~cm}^{-1}$ 
(compare to $41 \mathrm{~cm}^{-1}$ experimental value). This value is improved by $10 \mathrm{~cm}^{-1}$ though a small discrepancy is still there in comparison to the experimental value.

The ferro-antiferro exchange obtained from complexes $\mathbf{1}$ and $\mathbf{2}$ is interesting and may be due to subtle structural factors as argued below. It should also be mentioned that the Lines model employed to extract these parameters is semi-empirical and not fully ab initio as generally claimed. The alteration in the Js, however small, could be due to the very small structural distortions present inherently in complexes $\mathbf{1}$ and 2, and we have earlier established that a small change in bond length or bond angle can lead to the switching of ferromagnetic to antiferromagnetic behavior. ${ }^{30,47}$ Alternately, it could be purely dictated by the difference in anisotropy between $\mathbf{1}$ and 2. To ascertain the origin further, DFT calculations were performed on the X-ray structure of $\mathbf{1}$ and $\mathbf{2}$ where the anisotropic ions are substituted by the isotropic Gd ${ }^{\mathrm{III}}$ ions. These calculations clearly suggest the $J$ value is antiferromagnetic in $\mathbf{1}$ and ferromagnetic in 2. Since the sign is neatly reproduced in the DFT calculations, the nature of switch in the exchange clearly originates from small structural changes.

Further, we have also performed DFT calculations on complex 3, and this yields a ferromagnetic $J=+0.1 \mathrm{~cm}^{-1}$. The exchange values are verified with broken symmetry calculations performed by ORCA as well $\left(+0.07 \mathrm{~cm}^{-1}\right)$. The spin density plots are given in Figure 11, and the spin density of 6.95 on $\mathrm{Gd}^{\mathrm{III}}$ atom indicates spin delocalization. The mechanism of exchange coupling was studied in detail by us previously in $\{\mathrm{Gd} 2\}$ dimer bridged by $\mu$-oxo bridges. ${ }^{30}$ The nature of magnetic interaction strongly depends on the Gd-O-Gd bond angles. A change of angle even by $1^{\circ}$ can lead to a change in the nature of the coupling between the lanthanide ions. For complexes $\mathbf{2}$ and $\mathbf{3}$, one

\section{ACCEPTED MANUSCRIPT}


of these angles between Tb-O-Tb and Gd-O-Gd are $~ 114^{\circ}$, and for Dy-O-Dy it is $115^{\circ}$.These angles lie in the borderline area, and may be responsible for the switch in the nature of exchange.

\section{Conclusion}

In summary we have utilized a multi-dentate aroylhydrazone-based Schiff base ligand, 6-((bis(2hydroxyethyl)amino)- $N^{\prime}$-(2-hydroxybenzylidene)picolinohydrazide $\quad\left(\mathrm{LH}_{4}\right) \quad$ to assemble homometallic dinuclear lanthanide(III) complexes containing non-equivalent lanthanide metal centres $\left[\mathrm{Ln}_{2}\left(\mathrm{LH}_{2}\right)(\mathrm{LH})\left(\mathrm{CH}_{3} \mathrm{OH}\right)\left(\mathrm{N}_{3}\right)\right] \cdot \mathrm{xMeOH} \cdot \mathrm{yH}_{2} \mathrm{O}\left[\mathrm{1}, \mathrm{Ln}=\mathrm{Dy}{ }^{\mathrm{III}}, \mathrm{x}=0, \mathrm{y}=2 ; 2, \mathrm{Ln}=\mathrm{Tb}^{\mathrm{III}}, \mathrm{x}\right.$ $=1, \mathrm{y}=1]$. The non-equivalence of the lanthanide ions in these complexes arises from the variation of one terminal ligand. Thus, while one of the lanthanides has methanol as the ligand the other has an azide. In all the cases the lanthanide ions are nine-coordinate in a spherical capped square antiprism geometry (as determined by SHAPE analysis). Detailed magnetic studies revealed that 1 is a zero-field SMM with an effective energy barrier $\left(U_{\text {eff }}\right) 59(3) \mathrm{K}$ of magnetization reversal and a relaxation time of $\tau_{0}=10(4) \times 10^{-6} \mathrm{~s}$ while 2 shows a field-induced SMM behavior. Combined $a b$ initio and DFT calculations were performed to understand the observed magnetism. This reveals, that apart from the Kramers vs non-Kramers nature of the lanthanide ion, the individual variations in the coordination geometry around the lanthanide ions seem to play a subtle and important role in dictating the overall magnetic behavior. The change in the behavior of the nature of exchange has also been addressed in relation to the Ln-O-Ln bond angle which agrees with the earlier reported examples. The same magnetic structural correlation of the nature of exchange with metal oxo metal bond angle holds true for the nine coordinated asymmetric dinuclear lanthanide systems as well. 
Supplementary Information (SI): Crystal data information Table S1 for 3, Simulated singlecrystal data and experimental XRD pattern for 1-2, ESI-MS spectrum of complex 2 and 3, Molecular structure and bond length and bond angle of 2 and 3, Continuous Shape measures calculations, Supramolecular interactions, . Field dependence of molar magnetization plot at $2 \mathrm{~K}$ and Field dependence of molar magnetization plot in complexes and In-phase component of the ac magnetic susceptibility data for $\mathbf{1}$, Normalized Cole-Cole plot at several temperatures between 2 and $15 \mathrm{~K}$ for 1 under 0 Oe and 800 Oe, ac magnetic susceptibility data and Normalized ColeCole plot at several temperatures between 2 and $15 \mathrm{~K}$ for $\mathbf{1 5 \%}$, In-phase and out-of-phase components of the $a c$ magnetic susceptibility for 2 at $2 \mathrm{~K}$ in an applied DC magnetic field from 0 to 3000 Oe, In-phase ( $\chi_{M^{\prime}}$ ) and Out-of-phase ( $\left.\chi_{\mathrm{M}}{ }^{\prime \prime}\right)$ components of the $a c$ magnetic susceptibility data for $\mathbf{2}$ in 2800 Oe applied magnetic field, CASSCF +RASSI-SO+SINGLE_ANISO computed energies of the eight low-lying KDs and SINGLE_ANISO computed crystal field parameters $\mathbf{1}$ and 2, DFT computed spin density on Ln centre using Broken symmetry approach for complex 13.

\section{AUTHOR INFORMATION}

Corresponding Authors

*E-mail: vc@iitk.ac.in.

*E-mail: rajaraman@chem.iitb.ac.in.

*E-mail: fabrice.pointillart@univ-rennes1.fr.

ORCID

Fabrice Pointillart: 0000-0001-7601-1927

Gopalan Rajaraman: 0000-0001-6133-3026 
Vadapalli Chandrasekhar: 0000-0003-1968-2980

Notes

The authors declare no competing financial interest.

\section{ACKNOWLEDGMENTS}

We thank the Department of Science and Technology (DST), India; the CNRS, Université de Rennes 1, the European Commission through the ERC-CoG 725184 MULTIPROSMM (project no. 725184) for financial support, and also support for the Single Crystal CCD X-ray Diffractometer facility at IIT-Kanpur. V.C. is grateful to the DST for a J. C. Bose fellowship. P.K. and A.S. thanks University Grants Commission (UGC), India for Senior Research Fellowship. G.R. acknowledges DST/SERB for funding (CRG/2018/000430; DST/SJF/CSA-03/2018-10; SB/SJF/2019-20/12).We sincerely thank Mr. Prakash Nayak, NISER, Bhubanswar, Odisha, India for the PXRD measurements.

\section{References}

1. (a) Sessoli, R.; Powell, A. K., Strategies towards single molecule magnets based on lanthanide ions. Coord. Chem. Rev. 2009, 253, 2328-2341; (b) Woodruff, D. N.; Winpenny, R. E. P.; Layfield, 
R. A., Lanthanide Single-Molecule Magnets. Chem. Rev. 2013, 113, 5110-5148; (c) Feltham, H. L. C.; Brooker, S., Review of purely $4 \mathrm{f}$ and mixed-metal nd-4f single-molecule magnets containing only one lanthanide ion. Coord. Chem. Rev. 2014, 276, 1-33; (d) Liu, K.; Shi, W.; Cheng, P., Toward heterometallic single-molecule magnets: Synthetic strategy, structures and properties of 3d-4f discrete complexes. Coord. Chem. Rev. 2015, 289-290, 74-122; (e) Bar, A. K.; Pichon, C.; Sutter, J.-P., Magnetic anisotropy in two- to eight-coordinated transition-metal complexes: Recent developments in molecular magnetism. Coord. Chem. Rev. 2016, 308, 346-380; (f) Feng, M.; Tong, M.-L., Single Ion Magnets from 3d to 5f: Developments and Strategies. Chem. - Eur. J. 2018, 24, 7574-7594.

2. Sessoli, R.; Gatteschi, D.; Caneschi, A.; Novak, M. A., Magnetic bistability in a metal-ion cluster. Nature 1993, 365, 141-143.

3. (a) Dey, A.; Kalita, P.; Chandrasekhar, V., Lanthanide(III)-Based Single-Ion Magnets. ACS Omega 2018, 3, 9462-9475; (b) Liu, J.-L.; Chen, Y.-C.; Tong, M.-L., Symmetry strategies for high performance lanthanide-based single-molecule magnets. Chem. Soc. Rev. 2018, 47, 2431-2453.

4. Ishikawa, N.; Sugita, M.; Ishikawa, T.; Koshihara, S.-y.; Kaizu, Y., Lanthanide Double-Decker Complexes Functioning as Magnets at the Single-Molecular Level. J. Am. Chem. Soc. 2003, 125, 8694-8695.

5. (a) Ding, Y.-S.; Chilton, N. F.; Winpenny, R. E. P.; Zheng, Y.-Z., On Approaching the Limit of Molecular Magnetic Anisotropy: A Near-Perfect Pentagonal Bipyramidal Dysprosium(III) SingleMolecule Magnet. Angew. Chem. Int. Ed. 2016, 55, 16071-16074; (b) Liu, J.; Chen, Y.-C.; Liu, J.L.; Vieru, V.; Ungur, L.; Jia, J.-H.; Chibotaru, L. F.; Lan, Y.; Wernsdorfer, W.; Gao, S.; Chen, X.M.; Tong, M.-L., A Stable Pentagonal Bipyramidal Dy(III) Single-Ion Magnet with a Record Magnetization Reversal Barrier over 1000 K. J. Am. Chem. Soc. 2016, 138, 5441-5450; (c) Guo,

\section{ACCEPTED MANUSCRIPT}


F.-S.; Day, B. M.; Chen, Y.-C.; Tong, M.-L.; Mansikkamäki, A.; Layfield, R. A., A Dysprosium Metallocene Single-Molecule Magnet Functioning at the Axial Limit. Angew. Chem. Int. Ed. 2017, 56, 11445-11449; (d) Jiang, Z.; Sun, L.; Yang, Q.; Yin, B.; Ke, H.; Han, J.; Wei, Q.; Xie, G.; Chen, S., Excess axial electrostatic repulsion as a criterion for pentagonal bipyramidal DyIII single-ion magnets with high Ueff and TB. J. Mater. Chem. C 2018, 6, 4273-4280.

6. (a) Rinehart, J. D.; Fang, M.; Evans, W. J.; Long, J. R., A N23- Radical-Bridged Terbium Complex Exhibiting Magnetic Hysteresis at 14 K. J. Am. Chem. Soc. 2011, 133, 14236-14239; (b) Chen, Y.-C.; Liu, J.-L.; Ungur, L.; Liu, J.; Li, Q.-W.; Wang, L.-F.; Ni, Z.-P.; Chibotaru, L. F.; Chen, X.-M.; Tong, M.-L., Symmetry-Supported Magnetic Blocking at $20 \mathrm{~K}$ in Pentagonal Bipyramidal Dy(III) Single-Ion Magnets. J. Am. Chem. Soc. 2016, 138, 2829-2837; (c) Gupta, S. K.; Rajeshkumar, T.; Rajaraman, G.; Murugavel, R., An air-stable Dy(iii) single-ion magnet with high anisotropy barrier and blocking temperature. Chem. Sci. 2016, 7, 5181-5191; (d) Goodwin, C. A. P.; Ortu, F.; Reta, D.; Chilton, N. F.; Mills, D. P., Molecular magnetic hysteresis at 60 kelvin in dysprosocenium. Nature 2017, 548, 439-442; (e) Guo, F.-S.; Day, B. M.; Chen, Y.-C.; Tong, M.-L.; Mansikkamäki, A.; Layfield, R. A., Magnetic hysteresis up to 80 kelvin in a dysprosium metallocene single-molecule magnet. Science 2018, 362, 1400; (f) Randall McClain, K.; Gould, C. A.; Chakarawet, K.; Teat, S. J.; Groshens, T. J.; Long, J. R.; Harvey, B. G., High-temperature magnetic blocking and magneto-structural correlations in a series of dysprosium(iii) metallocenium single-molecule magnets. Chem. Sci. 2018, 9, 8492-8503.

7. Lu, J.; Guo, M.; Tang, J., Recent Developments in Lanthanide Single-Molecule Magnets. Chem. - Asian J. 2017, 12, 2772-2779.

8. (a) Guo, Y.-N.; Xu, G.-F.; Wernsdorfer, W.; Ungur, L.; Guo, Y.; Tang, J.; Zhang, H.-J.; Chibotaru, L. F.; Powell, A. K., Strong Axiality and Ising Exchange Interaction Suppress Zero- 
Field Tunneling of Magnetization of an Asymmetric Dy2 Single-Molecule Magnet. J. Am. Chem. Soc. 2011, 133, 11948-11951; (b) Long, J.; Habib, F.; Lin, P.-H.; Korobkov, I.; Enright, G.; Ungur, L.; Wernsdorfer, W.; Chibotaru, L. F.; Murugesu, M., Single-Molecule Magnet Behavior for an Antiferromagnetically Superexchange-Coupled Dinuclear Dysprosium(III) Complex. J. Am. Chem. Soc. 2011, 133, 5319-5328; (c) Rinehart, J. D.; Fang, M.; Evans, W. J.; Long, J. R., Strong exchange and magnetic blocking in N23--radical-bridged lanthanide complexes. Nat. Chemmun. 2011, 3, 538-542; (d) Mazarakioti, E. C.; Regier, J.; Cunha-Silva, L.; Wernsdorfer, W.; Pilkington, M.; Tang, J.; Stamatatos, T. C., Large Energy Barrier and Magnetization Hysteresis at $5 \mathrm{~K}$ for a Symmetric \{Dy2\} Complex with Spherical Tricapped Trigonal Prismatic DyIII Ions. Inorg. Chem. 2017, 56, 3568-3578; (e) Zhang, L.; Zhang, Y.-Q.; Zhang, P.; Zhao, L.; Guo, M.; Tang, J., SingleMolecule Magnet Behavior Enhanced by Synergic Effect of Single-Ion Anisotropy and Magnetic Interactions. Inorg. Chem. 2017, 56, 7882-7889; (f) Guo, F.-S.; Layfield, R. A., Strong direct exchange coupling and single-molecule magnetism in indigo-bridged lanthanide dimers. Chem. Commun. 2017, 53, 3130-3133; (g) Guo, M.; Zhang, Y.-Q.; Zhu, Z.; Tang, J., Dysprosium Compounds with Hula-Hoop-like Geometries: The Influence of Magnetic Anisotropy and Magnetic Interactions on Magnetic Relaxation. Inorg. Chem. 2018, 57, 12213-12221; (h) Han, T.; Ding, Y.-S.; Li, Z.-H.; Yu, K.-X.; Zhai, Y.-Q.; Chilton, N. F.; Zheng, Y.-Z., A dichlorido-bridged dinuclear Dy(iii) single-molecule magnet with an effective energy barrier larger than $600 \mathrm{~K}$. Chem. Commun. 2019, 55, 7930-7933; (i) Pointillart, F.; Le Gal, Y.; Golhen, S.; Cador, O.; Ouahab, L., Single-Molecule Magnet Behaviour in a Tetrathiafulvalene-Based Electroactive Antiferromagnetically Coupled Dinuclear Dysprosium(III) Complex. Chem. - Eur. J. 2011, 17, 10397-10404; (j) Chow, C. Y.; Bolvin, H.; Campbell, V. E.; Guillot, R.; Kampf, J. W.; Wernsdorfer, W.; Gendron, F.; Autschbach, J.; Pecoraro, V. L.; Mallah, T., Assessing the

\section{ACCEPTED MANUSCRIPT}


exchange coupling in binuclear lanthanide(iii) complexes and the slow relaxation of the magnetization in the antiferromagnetically coupled Dy2 derivative. Chem. Sci. 2015, 6, 41484159.

9. Wernsdorfer, W.; Aliaga-Alcalde, N.; Hendrickson, D. N.; Christou, G., Exchange-biased quantum tunnelling in a supramolecular dimer of single-molecule magnets. Nature 2002, 416, 406409.

10. (a) Aguilà, D.; Barrios, L. A.; Velasco, V.; Arnedo, L.; Aliaga-Alcalde, N.; Menelaou, M.; Teat, S. J.; Roubeau, O.; Luis, F.; Aromí, G., Lanthanide Contraction within a Series of Asymmetric Dinuclear [Ln2] Complexes. Chem. - Eur. J. 2013, 19, 5881-5891; (b) Aguilà, D.; Barrios, L. A.; Velasco, V.; Roubeau, O.; Repollés, A.; Alonso, P. J.; Sesé, J.; Teat, S. J.; Luis, F.; Aromí, G., Heterodimetallic [LnLn'] Lanthanide Complexes: Toward a Chemical Design of TwoQubit Molecular Spin Quantum Gates. J. Am. Chem. Soc. 2014, 136, 14215-14222; (c) GónzalezFabra, J.; Bandeira, N. A. G.; Velasco, V.; Barrios, L. A.; Aguilà, D.; Teat, S. J.; Roubeau, O.; Bo, C.; Aromí, G., Thermodynamic Stability of Heterodimetallic [LnLn'] Complexes: Synthesis and DFT Studies. Chem. - Eur. J. 2017, 23, 5117-5125; (d) Moreno Pineda, E.; Chilton, N. F.; Marx, R.; Dörfel, M.; Sells, D. O.; Neugebauer, P.; Jiang, S.-D.; Collison, D.; van Slageren, J.; McInnes,

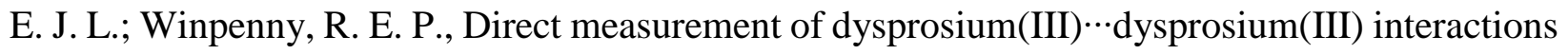
in a single-molecule magnet. Nat. Comm. 2014, 5, 5243; (e) Díaz-Ortega, I. F.; Herrera, J. M.; Aravena, D.; Ruiz, E.; Gupta, T.; Rajaraman, G.; Nojiri, H.; Colacio, E., Designing a Dy2 SingleMolecule Magnet with Two Well-Differentiated Relaxation Processes by Using a Nonsymmetric Bis-bidentate Bipyrimidine-N-Oxide Ligand: A Comparison with Mononuclear Counterparts. Inorg. Chem. 2018, 57, 6362-6375.

\section{ACCEPTED MANUSCRIPT}


11. (a) Chandrasekhar, V.; Bag, P.; Colacio, E., Octanuclear $\{\operatorname{Ln}(\mathrm{III}) 8\}(\mathrm{Ln}=\mathrm{Gd}$, Tb, Dy, Ho) Macrocyclic Complexes in a Cyclooctadiene-like Conformation: Manifestation of Slow Relaxation of Magnetization in the Dy(III) Derivative. Inorg. Chem. 2013, 52, 4562-4570; (b) Das, S.; Dey, A.; Kundu, S.; Biswas, S.; Narayanan, R. S.; Titos-Padilla, S.; Lorusso, G.; Evangelisti, M.; Colacio, E.; Chandrasekhar, V., Decanuclear Ln10 Wheels and Vertex-Shared Spirocyclic Ln5 Cores: Synthesis, Structure, SMM Behavior, and MCE Properties. Chem. - Eur. J. 2015, 21, 16955-16967; (c) Das, S.; Hossain, S.; Dey, A.; Biswas, S.; Sutter, J.-P.; Chandrasekhar, V., Molecular Magnets Based on Homometallic Hexanuclear Lanthanide(III) Complexes. Inorg. Chem. 2014, 53, 5020-5028; (d) Biswas, S.; Das, S.; Acharya, J.; Kumar, V.; van Leusen, J.; Kögerler, P.; Herrera, J. M.; Colacio, E.; Chandrasekhar, V., Homometallic DyIII Complexes of Varying Nuclearity from 2 to 21: Synthesis, Structure, and Magnetism. Chem. - Eur. J. 2017, 23, 5154-5170; (e) Biswas, S.; Bejoymohandas, K. S.; Das, S.; Kalita, P.; Reddy, M. L. P.; Oyarzabal, I.; Colacio, E.; Chandrasekhar, V., Mononuclear Lanthanide Complexes: Energy-Barrier Enhancement by Ligand Substitution in Field-Induced DyIII SIMs. Inorg. Chem. 2017, 56, 79857997; (f) Biswas, S.; Das, S.; Gupta, T.; Singh, S. K.; Pissas, M.; Rajaraman, G.; Chandrasekhar, V., Observation of Slow Relaxation and Single-Molecule Toroidal Behavior in a Family of Butterfly-Shaped Ln4 Complexes. Chem. - Eur. J. 2016, 22, 18532-18550; (g) Kalita, P.; Ahmed, N.; Bar, A. K.; Dey, S.; Jana, A.; Rajaraman, G.; Sutter, J.-P.; Chandrasekhar, V., Pentagonal Bipyramidal Ln(III) Complexes Containing an Axial Phosphine Oxide Ligand: Field-induced Single-ion Magnetism Behavior of the Dy(III) Analogues. Inorg. Chem. 2020, 59, 6603-6612.

12. (a) Guo, Y.-N.; Xu, G.-F.; Gamez, P.; Zhao, L.; Lin, S.-Y.; Deng, R.; Tang, J.; Zhang, H.-J., Two-Step Relaxation in a Linear Tetranuclear Dysprosium(III) Aggregate Showing SingleMolecule Magnet Behavior. J. Am. Chem. Soc. 2010, 132, 8538-8539; (b) Guo, Y.-N.; Chen, X.-

\section{ACCEPTED MANUSCRIPT}


H.; Xue, S.; Tang, J., Modulating Magnetic Dynamics of Three Dy2 Complexes through KetoEnol Tautomerism of the o-Vanillin Picolinoylhydrazone Ligand. Inorg. Chem. 2011, 50, 97059713; (c) Xue, S.; Guo, Y.-N.; Ungur, L.; Tang, J.; Chibotaru, L. F., Tuning the Magnetic Interactions and Relaxation Dynamics of Dy2 Single-Molecule Magnets. Chem. - Eur. J. 2015, 21, 14099-14106; (d) Ma, F.; Chen, Q.; Xiong, J.; Sun, H.-L.; Zhang, Y.-Q.; Gao, S., Modulating Slow Magnetic Relaxation of Dysprosium Compounds through the Position of Coordinating Nitrate Group. Inorg. Chem. 2017, 56, 13430-13436; (e) Bazhenova, T. A.; Mironov, V. S.; Yakushev, I. A.; Svetogorov, R. D.; Maximova, O. V.; Manakin, Y. V.; Kornev, A. B.; Vasiliev, A. N.; Yagubskii, E. B., End-to-End Azido-Bridged Lanthanide Chain Complexes (Dy, Er, Gd, and Y) with a Pentadentate Schiff-Base [N3O2] Ligand: Synthesis, Structure, and Magnetism. Inorg. Chem. 2020, 59, 563-578.

13. (a) Hong, C. S.; Koo, J.-e.; Son, S.-K.; Lee, Y. S.; Kim, Y.-S.; Do, Y., Unusual Ferromagnetic Couplings in Single End-to-End Azide-Bridged Cobalt(II) and Nickel(II) Chain Systems. Chem. - Eur. J. 2001, 7, 4243-4252; (b) Escuer, A.; Esteban, J.; Perlepes, S. P.; Stamatatos, T. C., The bridging azido ligand as a central "player" in high-nuclearity 3d-metal cluster chemistry. Coord. Chem. Rev. 2014, 275, 87-129.

14. (a) Vogel, A. I.; Furniss, B. S.; Hannaford, A. J.; Smith, P. W. G.; Tatchell, A. R., Vogel's textbook of practical organic chemistry. 5th ed. Longman: Harlow, 1989; (b) Williams, D. B. G.; Lawton, M., Drying of Organic Solvents: Quantitative Evaluation of the Efficiency of Several Desiccants. J. Org. Chem. 2010, 75, 8351-8354.

15. Zeng, X.; Coquière, D.; Alenda, A.; Garrier, E.; Prangé, T.; Li, Y.; Reinaud, O.; Jabin, I., Efficient Synthesis of Calix[6]tmpa: A New Calix[6]azacryptand with Unique Conformational and Host-Guest Properties. Chem. - Eur. J. 2006, 12, 6393-6402.

\section{ACCEPTED MANUSCRIPT}


16. SMART; SAINT, Software Reference manuals, Version 6.45. 2003.

17. Sheldrick, G., SADABS, software for empirical absorption correction, Ver. 2.05. University of Göttingen, Göttingen, Germany 2002.

18. SHELXTL Reference Manual; Bruker Analytical X-ray Systems, Inc., Madison, WI, 2000.

19. CrysAlis PRO, Rigaku Oxford Diffraction, Yarnton, England, 2015.

20. Sheldrick, G., A short history of SHELX. Acta Crystallographica Section A 2008, 64, 112122.

21. Dolomanov, O. V.; Bourhis, L. J.; Gildea, R. J.; Howard, J. A. K.; Puschmann, H., OLEX2: a complete structure solution, refinement and analysis program. J. Appl. Crystallogr. 2009, 42, 339341.

22. Bradenburg, K., Diamond, version 3.1 e. Crystal Impact GbR: Bonn, Germany 2005.

23. (a) Aquilante, F.; Autschbach, J.; Carlson, R. K.; Chibotaru, L. F.; Delcey, M. G.; De Vico, L.; Fdez. Galván, I.; Ferré, N.; Frutos, L. M.; Gagliardi, L.; Garavelli, M.; Giussani, A.; Hoyer, C. E.; Li Manni, G.; Lischka, H.; Ma, D.; Malmqvist, P. Å.; Müller, T.; Nenov, A.; Olivucci, M.; Pedersen, T. B.; Peng, D.; Plasser, F.; Pritchard, B.; Reiher, M.; Rivalta, I.; Schapiro, I.; SegarraMartí, J.; Stenrup, M.; Truhlar, D. G.; Ungur, L.; Valentini, A.; Vancoillie, S.; Veryazov, V.; Vysotskiy, V. P.; Weingart, O.; Zapata, F.; Lindh, R., Molcas 8: New capabilities for multiconfigurational quantum chemical calculations across the periodic table. J. Comput. Chem. 2016, 37, 506-541; (b) Duncan, J. A., MOLCAS 7.2. J. Am. Chem. Soc. 2009, 131, 2416-2416; (c) Veryazov, V.; Widmark, P.-O.; Serrano-Andrés, L.; Lindh, R.; Roos, B. O., 2MOLCAS as a development platform for quantum chemistry software. Int. J. Quantum Chem 2004, 100, 626635; (d) Aquilante, F.; De Vico, L.; Ferré, N.; Ghigo, G.; Malmqvist, P.-å.; Neogrády, P.; Pedersen, 
T. B.; Pitoňák, M.; Reiher, M.; Roos, B. O.; Serrano-Andrés, L.; Urban, M.; Veryazov, V.; Lindh, R., MOLCAS 7: The Next Generation. J. Comput. Chem. 2010, 31, 224-247.

24. (a) Ungur, L.; Van den Heuvel, W.; Chibotaru, L. F., Ab initio investigation of the noncollinear magnetic structure and the lowest magnetic excitations in dysprosium triangles. New J. Chem. 2009, 33, 1224-1230; (b) Chibotaru, L. F.; Ungur, L.; Aronica, C.; Elmoll, H.; Pilet, G.; Luneau, D., Structure, Magnetism, and Theoretical Study of a Mixed-Valence CoII3CoIII4 Heptanuclear Wheel: Lack of SMM Behavior despite Negative Magnetic Anisotropy. J. Am. Chem. Soc. 2008, 130, 12445-12455; (c) Chibotaru, L. F.; Ungur, L.; Soncini, A., The Origin of Nonmagnetic Kramers Doublets in the Ground State of Dysprosium Triangles: Evidence for a Toroidal Magnetic Moment. Angew. Chem. Int. Ed. 2008, 47, 4126-4129.

25. (a) Vignesh, K. R.; Langley, S. K.; Murray, K. S.; Rajaraman, G., Exploring the Influence of Diamagnetic Ions on the Mechanism of Magnetization Relaxation in $\{$ CoIII2LnIII2 $\}$ ( $\mathrm{Ln}=$ Dy, Tb, Ho) "Butterfly” Complexes. Inorg. Chem. 2017, 56, 2518-2532; (b) Chilton, N. F.; Anderson, R. P.; Turner, L. D.; Soncini, A.; Murray, K. S., PHI: A powerful new program for the analysis of anisotropic monomeric and exchange-coupled polynuclear d- and f-block complexes. J. Comput. Chem. 2013, 34, 1164-1175.

26. (a) Singh, M. K.; Rajaraman, G., Acquiring a record barrier height for magnetization reversal in lanthanide encapsulated fullerene molecules using DFT and ab initio calculations. Chem. Commun. 2016, 52, 14047-14050; (b) Singh, M. K.; Yadav, N.; Rajaraman, G., Record high magnetic exchange and magnetization blockade in Ln2@C79N (Ln = Gd(iii) and Dy(iii)) molecules: a theoretical perspective. Chem. Commun. 2015, 51, 17732-17735; (c) Bar, A. K.; Kalita, P.; Singh, M. K.; Rajaraman, G.; Chandrasekhar, V., Low-coordinate mononuclear lanthanide complexes as molecular nanomagnets. Coord. Chem. Rev. 2018, 367, 163-216.

\section{ACCEPTED MANUSCRIPT}


27. Lines, M. E., Orbital Angular Momentum in the Theory of Paramagnetic Clusters. J.Chem. Phys. 1971, 55, 2977-2984.

28. (a) Becke, A. D., Density-functional thermochemistry. III. The role of exact exchange. $J$. Chem. Phys. 1993, 98, 5648-5652; (b) Frisch, M.; Trucks, G.; Schlegel, H. B.; Scuseria, G. E.; Robb, M. A.; Cheeseman, J. R.; Scalmani, G.; Barone, V.; Mennucci, B.; Petersson, G., gaussian 09, Revision d. 01, Gaussian. Inc., Wallingford CT 2009, 201.

29. (a) Cundari, T. R.; Stevens, W. J., Effective core potential methods for the lanthanides. $J$. Chem. Phys. 1993, 98, 5555-5565; (b) Schäfer, A.; Huber, C.; Ahlrichs, R., Fully optimized contracted Gaussian basis sets of triple zeta valence quality for atoms Li to Kr. J. Chem. Phys. 1994, 100, 5829-5835.

30. Rajeshkumar, T.; Singh, S. K.; Rajaraman, G., A computational perspective on magnetic coupling, magneto-structural correlations and magneto-caloric effect of a ferromagnetically coupled \{GdIII-GdIII\} Pair. Polyhedron 2013, 52, 1299-1305.

31. Biswas, S.; Kumar, P.; Swain, A.; Gupta, T.; Kalita, P.; Kundu, S.; Rajaraman, G.; Chandrasekhar, V., Phosphonate-assisted tetranuclear lanthanide assemblies: observation of the toroidic ground state in the TbIII analogue. Dalton Trans. 2019, 48, 6421-6434.

32.(a) Cirera, J.; Ruiz, E.; Alvarez, S., Continuous Shape Measures as a Stereochemical Tool in Organometallic Chemistry. Organometallics 2005, 24, 1556-1562; (b) SHAPE: Continuous Shape Measures calculat ion 2.1; Electronic Structure Group, Universitat de Barcelona: Spain, 2013. 33. Zou, L.; Zhao, L.; Chen, P.; Guo, Y.-N.; Guo, Y.; Li, Y.-H.; Tang, J., Phenoxido and alkoxidobridged dinuclear dysprosium complexes showing single-molecule magnet behaviour. Dalton Trans. 2012, 41, 2966-2971.

34. Kahn, O., Molecular magnetism. VCH Publishers, Inc.(USA), 1993 1993, 393.

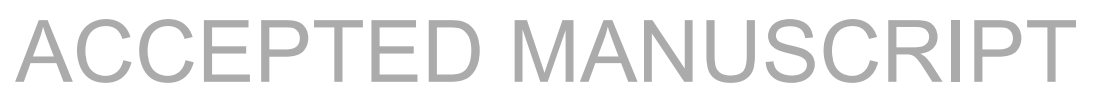


35. (a) Dekker, C.; Arts, A. F. M.; de Wijn, H. W.; van Duyneveldt, A. J.; Mydosh, J. A., Activated dynamics in a two-dimensional Ising spin glass: Activated dynamics in a twodimensional Ising spin glass: Rb2Cu1-xCoxF4. Phys. Rev. B 1989, 40, 11243-11251; (b) Cole, K. S.; Cole, R. H., Dispersion and Absorption in Dielectrics I. Alternating Current Characteristics. J. Chem. Phys. 1941, 9, 341-351.

36. (a) Car, P.-E.; Perfetti, M.; Mannini, M.; Favre, A.; Caneschi, A.; Sessoli, R., Giant field dependence of the low temperature relaxation of the magnetization in a dysprosium(iii)-DOTA complex. Chem. Commun. 2011, 47, 3751-3753; (b) Pointillart, F.; Flores Gonzalez, J.; Montigaud, V.; Tesi, L.; Cherkasov, V.; Le Guennic, B.; Cador, O.; Ouahab, L.; Sessoli, R.; Kuropatov, V., Redox- and solvato-magnetic switching in a tetrathiafulvalene-based triad singlemolecule magnet. Inorg. Chem. Front. 2020, 7, 2322-2334; (c) Lucaccini, E.; Sorace, L.; Perfetti, M.; Costes, J.-P.; Sessoli, R., Beyond the anisotropy barrier: slow relaxation of the magnetization in both easy-axis and easy-plane Ln(trensal) complexes. Chem. Commun. 2014, 50, 1648-1651; (d) Pedersen, K. S.; Dreiser, J.; Weihe, H.; Sibille, R.; Johannesen, H. V.; Sorensen, M. A.; Nielsen, B. E.; Sigrist, M.; Mutka, H.; Rols, S.; Bendix, J.; Piligkos, S. Design of Single-Molecule Magnets: Insufficiency of the Anisotropy Barrier as the Sole Criterion. Inorg. Chem. 2015, 54, $7600-7606)$

37. Abragam, A.; Bleaney, B., Electron paramagnetic resonance of transition ions. Oxford University Press: Oxford, 2012.

38. Goodwin, C. A. P.; Reta, D.; Ortu, F.; Chilton, N. F.; Mills, D. P., Synthesis and Electronic Structures of Heavy Lanthanide Metallocenium Cations. J. Am. Chem. Soc. 2017, 139, 1871418724. 
39. (a) Singh, A.; Shrivastava, K. N., Optical-acoustic two-phonon relaxation in spin systems. physica status solidi (b) 1979, 95, 273-277; (b) Shrivastava, K. N., Theory of Spin-Lattice Relaxation. physica status solidi (b) 1983, 117, 437-458.

40.(a) Li, M.; Wu, H.; Xia, Z.; Montigaud, V.; Cador, O.; Le Guennic, B.; Ke, H.; Wang, W.; Xie, G.; Chen, S., Bromine-bridged Dy2 single-molecule magnet: magnetic anisotropy driven by cis/trans stereoisomers. Chem. Commun. 2019, 55, 14661-14664; (b) Wu, H.; Li, M.; Xia, Z.; Montigaud, V.; Cador, O.; Le Guennic, B.; Ke, H.; Wang, W.; Xie, G.; Chen, S.; Gao, S., High temperature quantum tunnelling of magnetization and thousand kelvin anisotropy barrier in a Dy2 single-molecule magnet. Chem. Commun. 2021, 57, 371-374; (c) Hutchings, A.-J.; Habib, F.; Holmberg, R. J.; Korobkov, I.; Murugesu, M., Structural Rearrangement Through Lanthanide Contraction in Dinuclear Complexes. Inorg. Chem. 2014, 53, 2102-2112; (d) Lin, P.-H.; Sun, W.B.; Yu, M.-F.; Li, G.-M.; Yan, P.-F.; Murugesu, M., An unsymmetrical coordination environment leading to two slow relaxation modes in a Dy2 single-molecule magnet. Chem. Commun. 2011, 47, 10993-10995; (e) Zhang, W.-Y.; Chen, P.; Tian, Y.-M.; Li, H.-F.; Sun, W.-B.; Yan, P.-F., A series of salen-type asymmetric dinuclear Dy(iii) complexes: site-resolved two-step magnetic relaxation process. Cryst. Eng. Comm. 2018, 20, 777-786; (f) Huang, Y.; Li, J.-X.; Ge, Y.; Zhang, X.-M.; Xu, Y.; Li, Y.; Zhang, Y.-Q.; Yao, J.-L., Designing asymmetric Dy2 single-molecule magnets with two-step relaxation processes by the modification of the coordination environments of Dy(iii) ions. Dalton Trans. 2020, 49, 8976-8984; (g) Lyu, D.-P.; Zheng, J.-Y.; Li, Q.-W.; Liu, J.-L.; Chen, Y.-C.; Jia, J.-H.; Tong, M.-L., Construction of lanthanide single-molecule magnets with the "magnetic motif” [Dy(MQ)4]-. Inorg. Chem. Front. 2017, 4, 1776-1782

\section{ACCEPTED MANUSCRIPT}


41. Antal, P.; Drahoš, B.; Herchel R.; Trávníček, Z., Muffin-like lanthanide complexes with an N5O2-donor macrocyclic ligand showing field-induced single-molecule magnet behavior. Dalton Trans. 2016, 45, 15114.

42. (a) Mandal, L.; Biswas, S.; Cosquer, G.; Shen, Y.; Yamashita, M., Anion-driven structures and SMM behavior of dinuclear terbium and ytterbium complexes. Dalton Trans. 2018, 47, 1749317499; (b) Harriman, K. L. M.; Errulat, D.; Murugesu, M., Magnetic Axiality: Design Principles from Molecules to Materials. Trends in Chem. 2019, 1, 425-439.

43. (a) Tang, J.; Hewitt, I.; Madhu, N. T.; Chastanet, G.; Wernsdorfer, W.; Anson, C. E.; Benelli, C.; Sessoli, R.; Powell, A. K., Dysprosium Triangles Showing Single-Molecule Magnet Behavior of Thermally Excited Spin States. Angew. Chem. Int. Ed. 2006, 45, 1729-1733; (b) Marx, R.; Moro, F.; Dörfel, M.; Ungur, L.; Waters, M.; Jiang, S. D.; Orlita, M.; Taylor, J.; Frey, W.; Chibotaru, L. F.; van Slageren, J., Spectroscopic determination of crystal field splittings in lanthanide double deckers. Chem. Sci. 2014, 5, 3287-3293; (c) Rinehart, J. D.; Long, J. R., Exploiting single-ion anisotropy in the design of f-element single-molecule magnets. Chem. Sci. 2011, 2, 2078-2085. 44. Stevens, K., Matrix elements and operator equivalents connected with the magnetic properties of rare earth ions. Proceedings of the Physical Society. Section A 1952, 65, 209.

45. Chibotaru, L.; Ungur, L., The computer programs SINGLE_ANISO and POLY_ANISO. University of Leuven 2006, 2.

46. Boulon, M.-E.; Cucinotta, G.; Luzon, J.; Degl'Innocenti, C.; Perfetti, M.; Bernot, K.; Calvez, G.; Caneschi, A.; Sessoli, R., Magnetic Anisotropy and Spin-Parity Effect Along the Series of Lanthanide Complexes with DOTA. Angew. Chem. Int. Ed. 2013, 52, 350-354.

47. Dey, S.; Rajaraman, G., An approach to estimate the barrier height for magnetisation reversal in $\{$ Dy2 $\}$ SMMs using ab initio calculations. Dalton Trans., 2020, 49, 14781.

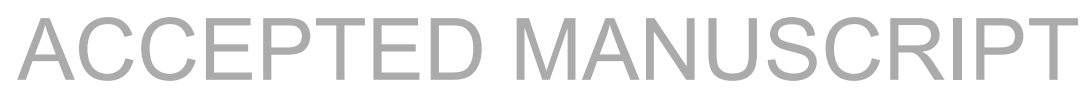


48. Rajeshkumar, T.; Rajaraman, G. Is a radical bridge a route to strong exchange interactions in lanthanide complexes? A computational examination. Chem. Commun. 2012, 48, 7856-7858

'For Table of Content Use Only'

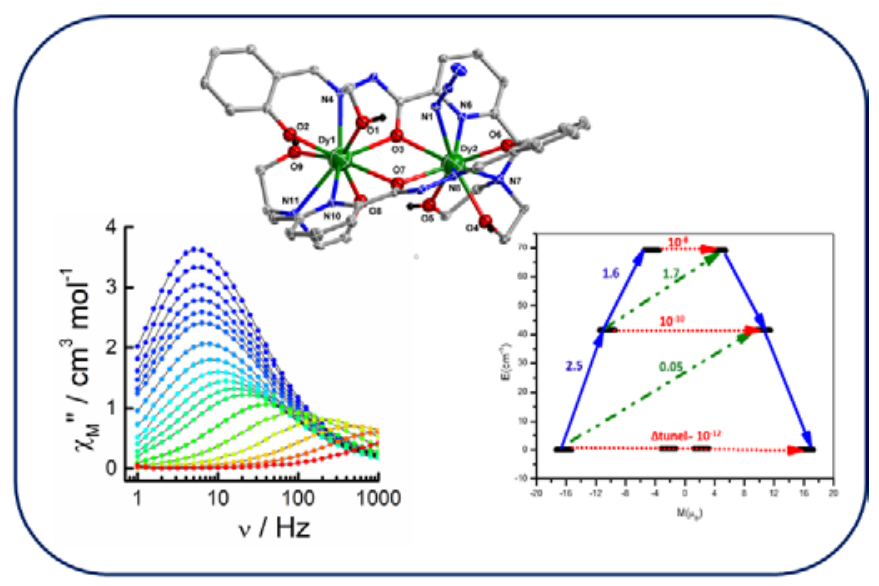

The syntheses, structures and combined theoretical and experimental magnetic properties of a family of dinuclear complexes having non-equivalent lanthanide ions have been studied which showed the Dy ${ }^{\mathrm{III}}$ analogue as a zero-field single-molecule magnet. 
ACCEPTED MANUSCRIPT 